\title{
General iterative algorithms for mixed equilibrium problems, variational inequalities and fixed point problems
}

\author{
Xiao-Jie Wang, Lu-Chuan Ceng ${ }^{*}$, Hui-Ying Hu and Shi-Xiu Li
}

"Correspondence:

zenglc@hotmail.com

Department of Mathematics,

Shanghai Normal University,

Shanghai, 200234, China

\begin{abstract}
In this paper, we introduce and analyze a general iterative algorithm for finding a common solution of a mixed equilibrium problem, a general system of variational inequalities and a fixed point problem of infinitely many nonexpansive mappings in a real Hilbert space. Under some mild conditions, we derive the strong convergence of the sequence generated by the proposed algorithm to a common solution, which also solves some optimization problem. The result presented in this paper improves and extends some corresponding ones in the earlier and recent literature.
\end{abstract}

MSC: 49J30; 47H10;47H15

Keywords: mixed equilibrium problem; nonexpansive mapping; variational inequality; fixed point; strongly positive bounded linear operator; inverse strongly monotone mapping

\section{Introduction}

Let $H$ be a real Hilbert space with the inner product $\langle\cdot, \cdot\rangle$ and the norm $\|\cdot\|$. Let $C$ be a nonempty, closed and convex subset of $H$, and let $T: C \rightarrow C$ be a nonlinear mapping. Throughout this paper, we use $F(T)$ to denote the fixed point set of $T$. A mapping $T: C \rightarrow$ $C$ is said to be nonexpansive if

$$
\|T x-T y\| \leq\|x-y\|, \quad \forall x, y \in C .
$$

Let $F: C \times C \rightarrow R$ be a real-valued bifunction and $\varphi: C \rightarrow R$ be a real-valued function, where $R$ is the set of real numbers. The so-called mixed equilibrium problem (MEP) is to find $x \in C$ such that

$$
F(x, y)+\varphi(y)-\varphi(x) \geq 0, \quad \forall y \in C,
$$

which was considered and studied in $[1,2]$. The set of solutions of MEP (1.2) is denoted by $\operatorname{MEP}(F, \varphi)$. In particular, whenever $\varphi \equiv 0, \operatorname{MEP}(1.2)$ reduces to the equilibrium problem (EP) of finding $x \in C$ such that

$$
F(x, y) \geq 0, \quad \forall y \in C,
$$

which was considered and studied in [3-7]. The set of solutions of the EP is denoted by $\mathrm{EP}(F)$. Given a mapping $A: C \rightarrow H$, let $F(x, y)=\langle A x, y-x\rangle$ for all $x, y \in C$. Then $x \in \operatorname{EP}(F)$ 
if and only if $\langle A x, y-x\rangle \geq 0$ for all $y \in C$. Numerous problems in physics, optimization and economics reduce to finding a solution of the EP.

Throughout this paper, assume that $F: C \times C \rightarrow R$ is a bifunction satisfying conditions (A1)-(A4) and that $\varphi: C \rightarrow R$ is a lower semicontinuous and convex function with restriction (B1) or (B2), where

(A1) $F(x, x)=0$ for all $x \in C$;

(A2) $F$ is monotone, i.e., $F(x, y)+F(y, x) \leq 0$ for any $x, y \in C$;

(A3) $F$ is upper-hemicontinuous, i.e., for each $x, y, z \in C$,

$$
\limsup _{t \rightarrow 0^{+}} F(t z+(1-t) x, y) \leq F(x, y)
$$

(A4) $F(x, \cdot)$ is convex and lower semicontinuous for each $x \in C$;

(B1) for each $x \in H$ and $r>0$, there exists a bounded subset $D_{x} \subset C$ and $y_{x} \in C$ such that for any $z \in C \backslash D_{x}$,

$$
F\left(z, y_{x}\right)+\varphi\left(y_{x}\right)-\varphi(z)+\frac{1}{r}\left\langle y_{x}-z, z-x\right\rangle<0
$$

(B2) $C$ is a bounded set.

The mappings $\left\{T_{n}\right\}_{n=1}^{\infty}$ are said to be an infinite family of nonexpansive self-mappings on $C$ if

$$
\left\|T_{n} x-T_{n} y\right\| \leq\|x-y\|, \quad \forall x, y \in C, n \geq 1,
$$

and denoted by $F\left(T_{n}\right)$ is the fixed point set of $T_{n}$, i.e., $F\left(T_{n}\right):=\left\{x \in C: T_{n} x=x\right\}$. Finding an optimal point in the intersection $\bigcap_{n=1}^{\infty} F\left(T_{n}\right)$ of fixed point sets of mappings $T_{n}, n \geq 1$, is a matter of interest in various branches of sciences.

Recently, many authors considered some iterative methods for finding a common element of the set of solutions of MEP (1.2) and the set of fixed points of nonexpansive mappings; see, e.g., $[2,8,9]$ and the references therein.

A mapping $A: C \rightarrow H$ is said to be

(i) monotone if

$$
\langle A x-A y, x-y\rangle \geq 0, \quad \forall x, y \in C
$$

(ii) strongly monotone if there exists a constant $\eta>0$ such that

$$
\langle A x-A y, x-y\rangle \geq \eta\|x-y\|^{2}, \quad \forall x, y \in C .
$$

In such a case, $A$ is said to be $\eta$-strongly monotone;

(iii) inverse-strongly monotone if there exists a constant $\zeta>0$ such that

$$
\langle A x-A y, x-y\rangle \geq \zeta\|A x-A y\|^{2}, \quad \forall x, y \in C .
$$

In such a case, $A$ is said to be $\zeta$-inverse-strongly monotone. 
Let $A: C \rightarrow H$ be a nonlinear mapping. The classical variational inequality problem (VIP) is to find $x^{*} \in C$ such that

$$
\left\langle A x^{*}, y-x^{*}\right\rangle \geq 0, \quad \forall y \in C .
$$

We use $\operatorname{VI}(C, A)$ to denote the set of solutions to VIP (1.4). One can easily see that VIP (1.4) is equivalent to a fixed point problem. That is, $u \in C$ is a solution of VIP (1.4) if and only if $u$ is a fixed point of the mapping $P_{C}(I-\lambda A)$, where $\lambda>0$ is a constant. Variational inequality theory has been studied quite extensively and has emerged as an important tool in the study of a wide class of obstacle, unilateral, free, moving, equilibrium problems. It is now well known that the variational inequalities are equivalent to the fixed point problems, the origin of which can be traced back to Lions and Stampacchia [10]. Not only the existence and uniqueness of solutions are important topics in the study of VIP (1.4), but also how to actually find a solution of VIP (1.4) is important. Up to now, there have been many iterative algorithms in the literature for finding approximate solutions of VIP (1.4) and its extended versions; see e.g., [3, 11-14].

Recently, Plubtieng and Punpaeng [15] and Ceng et al. [16,17] considered some iterative methods for VIP (1.4) and its extended versions and got some strong convergence theorems. As a generalization of VIP (1.4), the general system of variational inequalities (GSVI) is to find $\left(x^{*}, y^{*}\right) \in C \times C$ such that

$$
\begin{cases}\left\langle\mu_{1} B_{1} y^{*}+x^{*}-y^{*}, x-x^{*}\right\rangle \geq 0, & \forall x \in C, \\ \left\langle\mu_{2} B_{2} x^{*}+y^{*}-x^{*}, x-y^{*}\right\rangle \geq 0, & \forall x \in C,\end{cases}
$$

which $\mu_{1}$ and $\mu_{2}$ are two positive constants. GSVI (1.5) is considered and studied in [17], and the solution set of GSVI (1.5) is denoted by $\operatorname{GSVI}\left(C, B_{1}, B_{2}\right)$. In particular, whenever $B_{1}=B_{2}=A$ and $x^{*}=y^{*}$, GSVI (1.5) reduces to VIP (1.4). Ceng et al. [17] transformed GSVI (1.5) into a fixed point problem in the following way.

Lemma 1.1 (see [17]) For given $\bar{x}, \bar{y} \in C,(\bar{x}, \bar{y})$ is a solution of GSVI (1.5) if and only if $\bar{x}$ is a fixed point of the mapping $G: C \rightarrow C$ defined by

$$
G x=P_{C}\left(I-\mu_{1} B_{1}\right) P_{C}\left(I-\mu_{2} B_{2}\right) x, \quad \forall x \in C,
$$

where $\bar{y}=P_{C}\left(\bar{x}-\mu_{2} B_{2} \bar{x}\right)$ and $P_{C}$ is the projection of $H$ onto $C$.

In particular, if the mapping $B_{i}: C \rightarrow H$ is $\zeta_{i}$-inverse strongly monotone for $i=1,2$, then the mapping $G$ is nonexpansive provided $\mu_{i} \in\left(0,2 \zeta_{i}\right)$ for $i=1,2$. We denote by $\Gamma$ the fixed point set of the mapping $G$.

On the other hand, Moudafi [1] introduced the viscosity approximation method for nonexpansive mappings (see also [18] for further developments in both Hilbert spaces and Banach spaces).

A mapping $f: C \rightarrow C$ is called $\alpha$-contractive if there exists a constant $\alpha \in(0,1)$ such that

$$
\|f(x)-f(y)\| \leq \alpha\|x-y\|, \quad \forall x, y \in C .
$$


Let $f$ be a contraction on $C$. Starting with an arbitrary initial $x_{1} \in C$, define a sequence $\left\{x_{n}\right\}$ recursively by

$$
x_{n+1}=\alpha_{n} f\left(x_{n}\right)+\left(1-\alpha_{n}\right) T x_{n}, \quad \forall n \geq 0,
$$

where $T$ is a nonexpansive mapping of $C$ into itself and $\left\{\alpha_{n}\right\}$ is a sequence in $(0,1)$. It is proved in $[1,18]$ that under appropriate conditions imposed on $\left\{\alpha_{n}\right\}$ the sequence $\left\{x_{n}\right\}$ generated by (1.6) strongly converges to the unique solution $x^{*} \in F(T)$ to the VIP

$$
\left\langle(I-f) x^{*}, x-x^{*}\right\rangle \geq 0, \quad \forall x \in F(T) .
$$

A linear bounded operator $A$ is said to be $\bar{\gamma}$-strongly positive on $H$ if there exists a constant $\bar{\gamma} \in(0,1)$ such that

$$
\langle A x, x\rangle \geq \bar{\gamma}\|x\|^{2}, \quad \forall x \in H .
$$

Recently, Marino and Xu [19] introduced the following general iterative process:

$$
x_{n+1}=\alpha_{n} \gamma f\left(x_{n}\right)+\left(I-\alpha_{n} A\right) T x_{n}, \quad \forall n \geq 0,
$$

where $A$ is a strongly positive bounded linear operator on $H$. They proved that under appropriate conditions imposed on $\left\{\alpha_{n}\right\}$ the sequence $\left\{x_{n}\right\}$ generated by (1.8) converges strongly to the unique solution $x^{*} \in F(T)$ to the VIP

$$
\left\langle(A-\gamma f) x^{*}, x-x^{*}\right\rangle \geq 0, \quad \forall x \in F(T)
$$

which is the optimality condition for the minimization problem

$$
\min _{x \in F(T)} \frac{1}{2}\langle A x, x\rangle-h(x)
$$

where $h$ is a potential function for $\gamma f\left(\right.$ i.e., $h^{\prime}(x)=\gamma f(x)$ for all $x \in H$ ).

In 2007, Takahashi and Takahashi [5] introduced an iterative scheme by the viscosity approximation method for finding a common element of the set of solutions of the EP and the set of fixed points of a nonexpansive mapping in a real Hilbert space. Let $S: C \rightarrow H$ be a nonexpansive mapping. Starting with arbitrary initial $x_{1} \in H$, define sequences $\left\{x_{n}\right\}$ and $\left\{u_{n}\right\}$ recursively by

$$
\left\{\begin{array}{l}
F\left(u_{n}, y\right)+\frac{1}{r_{n}}\left\langle y-u_{n}, u_{n}-x_{n}\right\rangle \geq 0, \quad \forall y \in C, \\
x_{n+1}=\alpha_{n} f\left(x_{n}\right)+\left(1-\alpha_{n}\right) S u_{n}, \quad \forall n \geq 1 .
\end{array}\right.
$$

They proved that under appropriate conditions imposed on $\left\{\alpha_{n}\right\}$ and $\left\{r_{n}\right\}$, the sequences $\left\{x_{n}\right\}$ and $\left\{u_{n}\right\}$ converge strongly to $x^{*} \in F(S) \cap \operatorname{EP}(F)$, where $x^{*}=P_{F(S) \cap E P(F)} f\left(x^{*}\right)$.

Subsequently, Plubtieng and Punpaeng [15] introduced a general iterative process for finding a common element of the set of solutions of the EP and the set of fixed points of a nonexpansive mapping in a Hilbert space. 
Let $S: H \rightarrow H$ be a nonexpansive mapping. Starting with an arbitrary $x_{1} \in H$, define sequences $\left\{x_{n}\right\}$ and $\left\{u_{n}\right\}$ by

$$
\left\{\begin{array}{l}
F\left(u_{n}, y\right)+\frac{1}{r_{n}}\left\langle y-u_{n}, u_{n}-x_{n}\right\rangle \geq 0, \quad \forall y \in C, \\
x_{n+1}=\alpha_{n} \gamma f\left(x_{n}\right)+\left(1-\alpha_{n} A\right) S u_{n}, \quad \forall n \geq 1 .
\end{array}\right.
$$

They proved that under appropriate conditions imposed on $\left\{\alpha_{n}\right\}$ and $\left\{r_{n}\right\}$, the sequence $\left\{x_{n}\right\}$ generated by (1.11) converges strongly to the unique solution $x^{*} \in F(S) \cap \operatorname{EP}(F)$ to the VIP

$$
\left\langle(A-\gamma f) x^{*}, x-x^{*}\right\rangle \geq 0, \quad \forall x \in F(S) \cap \operatorname{EP}(F),
$$

which is the optimality condition for the minimization problem

$$
\min _{x \in F(S) \cap \mathrm{EP}(F)} \frac{1}{2}\langle A x, x\rangle-h(x),
$$

where $h$ is a potential function for $\gamma f$ (i.e., $h^{\prime}(x)=\gamma f(x)$ for all $x \in H$ ).

Let $\left\{T_{n}\right\}_{n=1}^{\infty}$ be an infinite family of nonexpansive self-mappings on $C$ and $\left\{\lambda_{n}\right\}_{n=1}^{\infty}$ be a sequence of nonnegative numbers in $[0,1]$. For any $n \geq 1$, define a mapping $W_{n}$ of $C$ into itself as follows:

$$
\left\{\begin{array}{l}
U_{n, n+1}=I, \\
U_{n, n}=\lambda_{n} T_{n} U_{n, n+1}+\left(1-\lambda_{n}\right) I, \\
U_{n, n-1}=\lambda_{n-1} T_{n-1} U_{n, n}+\left(1-\lambda_{n-1}\right) I, \\
\ldots, \\
U_{n, k}=\lambda_{k} T_{k} U_{n, k+1}+\left(1-\lambda_{k}\right) I, \\
U_{n, k-1}=\lambda_{k-1} T_{k-1} U_{n, k}+\left(1-\lambda_{k-1}\right) I, \\
\cdots \\
U_{n, 2}=\lambda_{2} T_{2} U_{n, 3}+\left(1-\lambda_{2}\right) I, \\
W_{n}=U_{n, 1}=\lambda_{1} T_{1} U_{n, 2}+\left(1-\lambda_{1}\right) I .
\end{array}\right.
$$

Such a mapping $W_{n}$ is called the $W$-mapping generated by $T_{n}, T_{n-1}, \ldots, T_{1}$ and $\lambda_{n}, \lambda_{n-1}$, $\ldots, \lambda_{1}$.

Recently, Yao et al. [6] proved the following strong convergence result.

Theorem 1.1 Let $C$ be a nonempty closed convex subset of a real Hilbert space H. Let F : $C \times C \rightarrow R$ be a bifunction satisfying conditions (A1)-(A4). Let $\left\{T_{n}\right\}_{n=1}^{\infty}$ be an infinite family of nonexpansive self-mappings on $C$ such that $\Omega:=\bigcap_{n=1}^{\infty} F\left(T_{n}\right) \cap \operatorname{EP}(F) \neq \emptyset$. Suppose that $\left\{\alpha_{n}\right\},\left\{\beta_{n}\right\}$ and $\left\{\gamma_{n}\right\}$ are three sequences in $(0,1)$ such that $\alpha_{n}+\beta_{n}+\gamma_{n}=1$ and $\left\{r_{n}\right\} \subset(0, \infty)$. Suppose that the following conditions are satisfied:

(i) $\lim _{n \rightarrow \infty} \alpha_{n}=0$ and $\sum_{n=1}^{\infty} \alpha_{n}=\infty$;

(ii) $0<\liminf _{n \rightarrow \infty} \beta_{n} \leq \limsup _{n \rightarrow \infty} \beta_{n}<1$;

(iii) $\liminf _{n \rightarrow \infty} r_{n}>0$ and $\lim _{n \rightarrow \infty}\left(r_{n+1}-r_{n}\right)=0$.

Let $f$ be a contraction on $H$, and let $x_{0} \in H$ be given arbitrarily. Then the sequences $\left\{x_{n}\right\}$ and $\left\{y_{n}\right\}$ generated iteratively by

$$
\left\{\begin{array}{l}
F\left(y_{n}, x\right)+\frac{1}{r_{n}}\left\langle x-y_{n}, y_{n}-x_{n}\right\rangle \geq 0, \quad \forall x \in C, \\
x_{n+1}=\alpha_{n} f\left(x_{n}\right)+\beta_{n} x_{n}+\gamma_{n} W_{n} y_{n},
\end{array}\right.
$$


converge strongly to $x^{*} \in \Omega$, the unique solution of the minimization problem

$$
\min _{x \in \Omega} \frac{1}{2}\|x\|^{2}-h(x)
$$

where $h$ is a potential function for $f$.

Very recently, Chen [20] proved the following strong convergence theorem.

Theorem 1.2 Let $C$ be a nonempty closed convex subset of a real Hilbert space H. Let $\left\{T_{n}\right\}_{n=1}^{\infty}$ be an infinite family of nonexpansive self-mappings on $C$ such that the common fixed point set $\Omega:=\bigcap_{n=1}^{\infty} F\left(T_{n}\right) \neq \emptyset$. Let $f: C \rightarrow H$ be an $\alpha$-contraction, and let $A: H \rightarrow H$ be a strongly positive bounded linear operator with a constant $\bar{\gamma}>0$. Let $\gamma$ be a constant such that $0<\gamma \alpha<\bar{\gamma}$. For an arbitrary initial point $x_{0} \in C$, one defines a sequence $\left\{x_{n}\right\}$ iteratively

$$
x_{n+1}=P_{C}\left[\alpha_{n} \gamma f\left(x_{n}\right)+\left(1-\alpha_{n} A\right) W_{n} x_{n}\right], \quad \forall n \geq 0,
$$

where $\left\{\alpha_{n}\right\}$ is a real sequence in $[0,1]$. Assume that the sequence $\left\{\alpha_{n}\right\}$ satisfies the following conditions:

(C1) $\lim _{n \rightarrow \infty} \alpha_{n}=0$;

(C2) $\sum_{n=1}^{\infty} \alpha_{n}=\infty$.

Then the sequence $\left\{x_{n}\right\}$ generated by (1.14) converges in norm to the unique solution $x^{*} \in \Omega$, which solves the VIP

$$
\left\langle(A-\gamma f) x^{*}, x^{*}-x\right\rangle \leq 0, \quad \forall x \in \Omega
$$

More recently, Rattanaseeha [7] introduced an iterative algorithm:

$$
\left\{\begin{array}{l}
x_{1} \in H \quad \text { arbitrarily given, } \\
F\left(u_{n}, y\right)+\frac{1}{r_{n}}\left\langle y-u_{n}, u_{n}-x_{n}\right\rangle \geq 0, \quad \forall y \in C, \\
x_{n+1}=P_{C}\left[\alpha_{n} \gamma f\left(x_{n}\right)+\left(I-\alpha_{n} A\right) W_{n} x_{n}\right], \quad \forall n \geq 1,
\end{array}\right.
$$

and proved the following strong convergence theorem.

Theorem 1.3 Let $C$ be a nonempty closed convex subset of a real Hilbert space H. Let $F$ be a bifunction from $C \times C$ to $R$ satisfying (A1)-(A4). Let $f$ be an $\alpha$-contraction on $H$ with $\alpha \in(0,1)$, and let $\left\{T_{n}\right\}_{n=1}^{\infty}$ be an infinite family of nonexpansive self-mappings on $C$ such that $\Omega:=\bigcap_{n=1}^{\infty} F\left(T_{n}\right) \cap \mathrm{EP}(F) \neq \emptyset$. Let $A: H \rightarrow H$ be a $\bar{\gamma}$-strongly positive bounded linear operator with $0<\gamma<\frac{\bar{\gamma}}{\alpha}$. Let $\lambda_{1}, \lambda_{2}, \ldots$ be a sequence of real numbers such that $0<\lambda_{n} \leq b<1$, $n=1,2, \ldots$. Let $W_{n}$ be the $W$-mapping of $C$ into itself generated by (1.13). Let $W$ be defined by $W x=\lim _{n \rightarrow \infty} W_{n} x, \forall x \in C$. Let $\left\{x_{n}\right\}$ and $\left\{u_{n}\right\}$ be sequences generated by (1.16), where $\left\{\alpha_{n}\right\}$ is a sequence in $(0,1)$ and $\left\{r_{n}\right\}$ is a sequence in $(0, \infty)$ such that the following conditions hold:

(C1) $\lim _{n \rightarrow \infty} \alpha_{n}=0$;

(C2) $\sum_{n=1}^{\infty} \alpha_{n}=\infty$;

(C3) $\lim _{n \rightarrow \infty} r_{n}=r>0$. 
Then both $\left\{x_{n}\right\}$ and $\left\{u_{n}\right\}$ converge strongly to $x^{*} \in \Omega$, which is the unique solution to the VIP

$$
\left\langle(A-\gamma f) x^{*}, x^{*}-x\right\rangle \leq 0, \quad \forall x \in \Omega
$$

Equivalently, $x^{*}=P_{\Omega}(I-A+\gamma f) x^{*}$.

Let $F: C \times C \rightarrow R$ be a real-valued bifunction, $\varphi: C \rightarrow R$ be a real-valued function, $A$ be a strongly positive bounded linear operator on $H$, and $f$ be an $l$-Lipschitz continuous mapping on $H$. Motivated by the above facts, in this paper we propose and analyze a general iterative algorithm:

$$
\left\{\begin{array}{l}
x_{1} \in H \quad \text { arbitrarily given, } \\
F\left(u_{n}, y\right)+\varphi(y)-\varphi\left(u_{n}\right)+\frac{1}{r_{n}}\left(y-u_{n}, u_{n}-x_{n}\right\rangle \geq 0, \quad \forall y \in C, \\
x_{n+1}=P_{C}\left[\alpha_{n} \gamma f\left(x_{n}\right)+\beta_{n} x_{n}+\left(\left(1-\beta_{n}\right) I-\alpha_{n} A\right) W_{n} G u_{n}\right], \quad \forall n \geq 1,
\end{array}\right.
$$

where $\left\{\alpha_{n}\right\},\left\{\beta_{n}\right\} \subset(0,1),\left\{r_{n}\right\} \subset(0, \infty), G=P_{C}\left(I-\mu_{1} B_{1}\right) P_{C}\left(I-\mu_{2} B_{2}\right)$, and $W_{n}$ is the $W$-mapping defined by (1.13), for finding a common solution of MEP (1.2), GSVI (1.5) and the fixed point problem of an infinite family of nonexpansive self-mappings $\left\{T_{n}\right\}_{n=1}^{\infty}$ on $C$. It is proven that under mild conditions imposed on $\left\{\alpha_{n}\right\},\left\{\beta_{n}\right\}$ and $\left\{r_{n}\right\}$, the sequences $\left\{x_{n}\right\}$ and $\left\{u_{n}\right\}$ generated by (1.17) converge strongly to $x^{*} \in \Omega:=\bigcap_{n=1}^{\infty} F\left(T_{n}\right) \cap \operatorname{MEP}(F, \varphi) \cap \Gamma$, which is the unique solution of the VIP

$$
\left\langle(A-\gamma f) x^{*}, x^{*}-x\right\rangle \leq 0, \quad \forall x \in \Omega
$$

or, equivalently, the unique solution of the minimization problem

$$
\min _{x \in \Omega} \frac{1}{2}\langle A x, x\rangle-h(x)
$$

where $h$ is a potential function for $\gamma f$ (i.e., $h^{\prime}(x)=\gamma f(x)$ for all $x \in H$ ). Whenever $B_{1} \equiv$ $B_{2} \equiv 0$ and $\varphi \equiv 0$, our problem of finding $x^{*} \in \bigcap_{n=1}^{\infty} F\left(T_{n}\right) \cap \operatorname{MEP}(F, \varphi) \cap \Gamma$ reduces to the problem of finding $x^{*} \in \bigcap_{n=1}^{\infty} F\left(T_{n}\right) \cap \mathrm{EP}(F)$ in Theorem 1.3. The results presented in this paper improve and extend the corresponding theorems in [7].

\section{Preliminaries}

Let $H$ be a real Hilbert space with the inner product $\langle\cdot, \cdot\rangle$ and the norm $\|\cdot\|$, and let $C$ be a closed convex subset of $H$. We indicate weak convergence and strong convergence by using the notations $\rightarrow$ and $\rightarrow$, respectively. A mapping $f: C \rightarrow H$ is called $l$-Lipschitz continuous if there exists a constant $l \geq 0$ such that

$$
\|f(x)-f(y)\| \leq l\|x-y\|, \quad \forall x, y \in C
$$

In particular, if $l=1$ then $f$ is called a nonexpansive mapping; if $l \in[0,1)$ then $f$ is called a contraction. Recall that a mapping $T: H \rightarrow H$ is said to be a firmly nonexpansive mapping if

$$
\|T x-T y\|^{2} \leq\langle T x-T y, x-y\rangle, \quad \forall x, y \in H .
$$


The metric (or nearest point) projection from $H$ onto $C$ is the mapping $P_{C}: H \rightarrow C$ which assigns to each point $x \in H$ the unique point $P_{C} x \in C$ satisfying the property

$$
\left\|x-P_{C} x\right\|=\inf _{y \in C}\|x-y\|=: d(x, C) .
$$

Some important properties of projections are gathered in the following proposition.

Proposition 2.1 For given $x \in H$ and $z \in C$ :

(i) $z=P_{C} x \Leftrightarrow\langle x-z, y-z\rangle \leq 0, \forall y \in C$;

(ii) $z=P_{C} x \Leftrightarrow\|x-z\|^{2} \leq\|x-y\|^{2}-\|y-z\|^{2}, \forall y \in C$;

(iii) $\left\langle P_{C} x-P_{C} y, x-y\right\rangle \geq\left\|P_{C} x-P_{C} y\right\|^{2}, \forall y \in H$.

Consequently, $P_{C}$ is a firmly nonexpansive mapping of $H$ onto $C$ and hence nonexpansive and monotone.

Let $A: C \rightarrow H$ be an $\alpha$-inverse-strongly monotone mapping. Then it is obvious that $A$ is monotone and $\frac{1}{\alpha}$-Lipschitz continuous. We also have that for all $x, y \in C$ and $\lambda>0$,

$$
\begin{aligned}
\|(I-\lambda A) x-(I-\lambda A) y\|^{2} & =\|x-y-\lambda(A x-A y)\|^{2} \\
& =\|x-y\|^{2}-2 \lambda\langle A x-A y, x-y\rangle+\lambda^{2}\|A x-A y\|^{2} \\
& \leq\|x-y\|^{2}+\lambda(\lambda-2 \alpha)\|A x-A y\|^{2} .
\end{aligned}
$$

So, whenever $\lambda \leq 2 \alpha, I-\lambda A$ is a nonexpansive mapping.

Given a positive number $r>0$. Let $T_{r}^{(F, \varphi)}: H \rightarrow C$ be the solution set of the auxiliary mixed equilibrium problem, that is, for each $x \in H$,

$$
T_{r}^{(F, \varphi)} x:=\left\{y \in C: F(y, z)+\varphi(z)-\varphi(y)+\frac{1}{r}\langle y-x, z-y\rangle \geq 0, \forall z \in C\right\} .
$$

Proposition 2.2 (see $[2,8]$ ) Let $C$ be a nonempty closed convex subset of a real Hilbert space $H$. Let $F: C \times C \rightarrow R$ be a bifunction satisfying conditions (A1)-(A4), and let $\varphi$ : $C \rightarrow R$ be a lower semicontinuous and convex function with restriction (B1) or (B2). Then the following hold:

(a) for each $x \in H, T_{r}^{(F, \varphi)} x \neq \emptyset$;

(b) $T_{r}^{(F, \varphi)}$ is single-valued;

(c) $T_{r}^{(F, \varphi)}$ is firmly nonexpansive, i.e., for any $x, y \in H$,

$$
\left\|T_{r}^{(F, \varphi)} x-T_{r}^{(F, \varphi)} y\right\|^{2} \leq\left\langle T_{r}^{(F, \varphi)} x-T_{r}^{(F, \varphi)} y, x-y\right\rangle ;
$$

(d) for all $s, t>0$ and $x \in H$,

$$
\left\|T_{s}^{(F, \varphi)} x-T_{t}^{(F, \varphi)} x\right\|^{2} \leq \frac{s-t}{s}\left\langle T_{s}^{(F, \varphi)} x-x, T_{s}^{(F, \varphi)} x-T_{t}^{(F, \varphi)} x\right\rangle ;
$$

(e) $F\left(T_{r}^{(F, \varphi)}\right)=\operatorname{MEP}(F, \varphi)$;

(f) $\operatorname{MEP}(F, \varphi)$ is closed and convex. 
Remark 2.1 It is easy to see from conclusions (c) and (d) in Proposition 2.2 that

$$
\left\|T_{r}^{(F, \varphi)} x-T_{r}^{(F, \varphi)} y\right\| \leq\|x-y\|, \quad \forall r>0, x, y \in H
$$

and

$$
\left\|T_{s}^{(F, \varphi)} x-T_{t}^{(F, \varphi)} x\right\| \leq \frac{|s-t|}{s}\left\|T_{s}^{(F, \varphi)} x-x\right\|, \quad \forall s, t>0, x \in H .
$$

We need some facts and tools in a real Hilbert space $H$ which are listed as lemmas below.

Lemma 2.1 Let $X$ be a real inner product space. Then the following inequality holds:

$$
\|x+y\|^{2} \leq\|x\|^{2}+2\langle y, x+y\rangle, \quad \forall x, y \in X .
$$

Lemma 2.2 Let $H$ be a real Hilbert space. Then the following hold:

(a) $\|x-y\|^{2}=\|x\|^{2}-\|y\|^{2}-2\langle x-y, y\rangle$ for all $x, y \in H$;

(b) $\|\lambda x+\mu y\|^{2}=\lambda\|x\|^{2}+\mu\|y\|^{2}-\lambda \mu\|x-y\|^{2}$ for all $x, y \in H$ and $\lambda, \mu \in[0,1]$ with $\lambda+\mu=1$

(c) If $\left\{x_{n}\right\}$ is a sequence in $H$ such that $x_{n} \rightarrow x$, it follows that

$$
\limsup _{n \rightarrow \infty}\left\|x_{n}-y\right\|^{2}=\limsup _{n \rightarrow \infty}\left\|x_{n}-x\right\|^{2}+\|x-y\|^{2}, \quad \forall y \in H .
$$

We have the following crucial lemmas concerning the $W$-mappings defined by (1.13).

Lemma 2.3 (see [21, Lemma 3.2]) Let $\left\{T_{n}\right\}_{n=1}^{\infty}$ be a sequence ofnonexpansive self-mappings on $C$ such that $\bigcap_{n=1}^{\infty} F\left(T_{n}\right) \neq \emptyset$, and let $\left\{\lambda_{n}\right\}$ be a sequence in $(0, b]$ for some $b \in(0,1)$. Then, for every $x \in C$ and $k \geq 1$, the limit $\lim _{n \rightarrow \infty} U_{n, k} x$ exists, where $U_{n, k}$ is defined by (1.13).

Remark 2.2 (see [6, Remark 3.1]) It can be known from Lemma 2.3 that if $D$ is a nonempty bounded subset of $C$, then for $\epsilon>0$ there exists $n_{0} \geq k$ such that for all $n>n_{0}$,

$$
\sup _{x \in D}\left\|U_{n, k} x-U_{k} x\right\| \leq \epsilon
$$

Remark 2.3 (see [6, Remark 3.2]) Utilizing Lemma 2.3, we define a mapping $W: C \rightarrow C$ as follows:

$$
W x=\lim _{n \rightarrow \infty} W_{n} x=\lim _{n \rightarrow \infty} U_{n, 1} x, \quad \forall x \in C .
$$

Such a $W$ is called the $W$-mapping generated by $T_{1}, T_{2}, \ldots$ and $\lambda_{1}, \lambda_{2}, \ldots$. Since $W_{n}$ is nonexpansive, $W: C \rightarrow C$ is also nonexpansive. Indeed, observe that for each $x, y \in C$,

$$
\|W x-W y\|=\lim _{n \rightarrow \infty}\left\|W_{n} x-W_{n} y\right\| \leq\|x-y\| .
$$

If $\left\{x_{n}\right\}$ is a bounded sequence in $C$, then we put $D=\left\{x_{n}: n \geq 1\right\}$. Hence, it is clear from Remark 2.2 that for an arbitrary $\epsilon>0$, there exists $N_{0} \geq 1$ such that for all $n>N_{0}$,

$$
\left\|W_{n} x_{n}-W x_{n}\right\|=\left\|U_{n, 1} x_{n}-U_{1} x_{n}\right\| \leq \sup _{x \in D}\left\|U_{n, 1} x-U_{1} x\right\| \leq \epsilon
$$


This implies that

$$
\lim _{n \rightarrow \infty}\left\|W_{n} x_{n}-W x_{n}\right\|=0
$$

Lemma 2.4 (see [21, Lemma 3.3]) Let $\left\{T_{n}\right\}_{n=1}^{\infty}$ be a sequence of nonexpansive self-mappings on $C$ such that $\bigcap_{n=1}^{\infty} F\left(T_{n}\right) \neq \emptyset$, and let $\left\{\lambda_{n}\right\}$ be a sequence in $(0, b]$ for some $b \in(0,1)$. Then $F(W)=\bigcap_{n=1}^{\infty} F\left(T_{n}\right)$.

Lemma 2.5 (see [22, demiclosedness principle]) Let C be a nonempty closed convex subset of a real Hilbert space $H$. Let $T$ be a nonexpansive self-mapping on $C$ with $F(T) \neq \emptyset$. Then $I-T$ is demiclosed. That is, whenever $\left\{x_{n}\right\}$ is a sequence in $C$ weakly converging to some $x \in C$ and the sequence $\left\{(I-T) x_{n}\right\}$ strongly converges to some $y$, it follows that $(I-T) x=y$. Here I is the identity operator of $H$.

Lemma 2.6 Let $A: C \rightarrow H$ be a monotone mapping. In the context of the variational inequality problem, the characterization of the projection (see Proposition 2.1(i)) implies

$$
u \in \operatorname{VI}(C, A) \quad \Leftrightarrow \quad u=P_{C}(u-\lambda A u), \quad \forall \lambda>0 .
$$

Lemma 2.7 (see [19]) Let $A$ be a $\bar{\gamma}$-strongly positive bounded linear operator on $H$ and assume $0<\rho \leq\|A\|^{-1}$. Then $\|I-\rho A\| \leq 1-\rho \bar{\gamma}$.

Lemma 2.8 (see [23]) Assume that $\left\{a_{n}\right\}$ is a sequence of nonnegative real numbers such that

$$
a_{n+1} \leq\left(1-\gamma_{n}\right) a_{n}+\sigma_{n} \gamma_{n}, \quad \forall n \geq 1,
$$

where $\left\{\gamma_{n}\right\}$ is a sequence in $[0,1]$ and $\left\{\sigma_{n}\right\}$ is a real sequence such that

(i) $\sum_{n=1}^{\infty} \gamma_{n}=\infty$;

(ii) $\lim \sup _{n \rightarrow \infty} \sigma_{n} \leq 0$ or $\sum_{n=1}^{\infty}\left|\sigma_{n} \gamma_{n}\right|<\infty$.

Then $\lim _{n \rightarrow \infty} a_{n}=0$.

\section{Main results}

We will introduce and analyze a general iterative algorithm for finding a common solution of MEP (1.2), GSVI (1.5) and the fixed point problem of infinitely many nonexpansive mappings in a real Hilbert space. Under appropriate conditions imposed on the parameter sequences, we will prove strong convergence of the proposed algorithm.

Theorem 3.1 Let $C$ be a nonempty closed convex subset of a real Hilbert space H. Let $F$ be a bifunction from $C \times C$ to $R$ satisfying conditions (A1)-(A4), and let $\varphi: C \rightarrow R$ be a lower semicontinuous and convex function with restriction (B1) or (B2). Let the mapping $B_{i}: C \rightarrow H$ be $\zeta_{i}$-inverse strongly monotone for $i=1,2$. Let $\left\{T_{n}\right\}_{n=1}^{\infty}$ be a sequence of nonexpansive self-mappings on $C$, and let $\left\{\lambda_{n}\right\}$ be a sequence in $(0, b]$ for some $b \in(0,1)$. Let $A$ be a $\bar{\gamma}$-strongly positive bounded linear operator on $H$ and $f: H \rightarrow H$ be an l-Lipschitz continuous mapping with $\gamma l<\bar{\gamma}$. Let $W_{n}$ be the $W$-mapping defined by (1.13). Assume that $\Omega:=\bigcap_{n=1}^{\infty} F\left(T_{n}\right) \cap \operatorname{MEP}(F, \varphi) \cap \Gamma \neq \emptyset$, where $\Gamma$ is the fixed point set of the mapping $G=P_{C}\left(I-\mu_{1} B_{1}\right) P_{C}\left(I-\mu_{2} B_{2}\right)$ with $\mu_{i} \in\left(0,2 \zeta_{i}\right)$ for $i=1,2$. Let $\left\{\alpha_{n}\right\}$ and $\left\{\beta_{n}\right\}$ be two sequences in $(0,1)$ and $\left\{r_{n}\right\}$ be a sequence in $(0, \infty)$ such that: 
(i) $\lim _{n \rightarrow \infty} \alpha_{n}=0, \sum_{n=1}^{\infty} \alpha_{n}=\infty$ and $\sum_{n=1}^{\infty}\left|\alpha_{n+1}-\alpha_{n}\right|<\infty$;

(ii) $0<\liminf _{n \rightarrow \infty} \beta_{n} \leq \lim \sup _{n \rightarrow \infty} \beta_{n}<1$ and $\sum_{n=1}^{\infty}\left|\beta_{n+1}-\beta_{n}\right|<\infty$;

(iii) $\liminf _{n \rightarrow \infty} r_{n}>0$ and $\sum_{n=1}^{\infty}\left|r_{n+1}-r_{n}\right|<\infty$.

Given $x_{1} \in H$ arbitrarily, the sequences $\left\{x_{n}\right\}$ and $\left\{u_{n}\right\}$ generated iteratively by

$$
\left\{\begin{array}{l}
F\left(u_{n}, y\right)+\varphi(y)-\varphi\left(u_{n}\right)+\frac{1}{r_{n}}\left\langle y-u_{n}, u_{n}-x_{n}\right\rangle \geq 0, \quad \forall y \in C, \\
x_{n+1}=P_{C}\left[\alpha_{n} \gamma f\left(x_{n}\right)+\beta_{n} x_{n}+\left(\left(1-\beta_{n}\right) I-\alpha_{n} A\right) W_{n} G u_{n}\right], \quad \forall n \geq 1
\end{array}\right.
$$

converge strongly to $x^{*} \in \Omega$, which is the unique solution of the VIP

$$
\left\langle(A-\gamma f) x^{*}, x^{*}-x\right\rangle \leq 0, \quad \forall x \in \Omega
$$

or, equivalently, the unique solution of the minimization problem

$$
\min _{x \in \Omega} \frac{1}{2}\langle A x, x\rangle-h(x)
$$

where $h$ is a potential function for $\gamma f$.

Proof Taking into account that $\lim _{n \rightarrow \infty} \alpha_{n}=0$ and $0<\liminf _{n \rightarrow \infty} \beta_{n} \leq \limsup _{n \rightarrow \infty} \beta_{n}<1$, we may assume, without loss of generality, that $\alpha_{n} \leq\left(1-\beta_{n}\right)\|A\|^{-1}$ for all $n \geq 1$. Since $A$ is a $\bar{\gamma}$-strongly positive bounded linear operator on $H$, we know that $\|A\|=\sup \{\langle A u, u\rangle: u \in$ $H,\|u\|=1\} \geq \bar{\gamma}$,

$$
\|I-A\|=\sup \{\langle(I-A) u, u\rangle: u \in H,\|u\|=1\} \leq 1-\bar{\gamma},
$$

and for $u \in H$ with $\|u\|=1$,

$$
\begin{aligned}
\left\langle\left(\left(1-\beta_{n}\right) I-\alpha_{n} A\right) u, u\right\rangle & =1-\beta_{n}-\alpha_{n}\langle A u, u\rangle \\
& \geq 1-\beta_{n}-\alpha_{n}\|A\| \geq 0,
\end{aligned}
$$

that is, $\left(1-\beta_{n}\right) I-\alpha_{n} A$ is positive. It follows that

$$
\begin{aligned}
\left\|\left(1-\beta_{n}\right) I-\alpha_{n} A\right\| & =\sup \left\{\left\langle\left(\left(1-\beta_{n}\right) I-\alpha_{n} A\right) u, u\right\rangle: u \in H,\|u\|=1\right\} \\
& =\sup \left\{1-\beta_{n}-\alpha_{n}\langle A u, u\rangle: u \in H,\|u\|=1\right\} \\
& \leq 1-\beta_{n}-\alpha_{n} \bar{\gamma} .
\end{aligned}
$$

We observe that $P_{\Omega}(\gamma f+(I-A))$ is a contraction. Indeed, for all $x, y \in H$, we have

$$
\begin{aligned}
\left\|P_{\Omega}(\gamma f+(I-A)) x-P_{\Omega}(\gamma f+(I-A)) y\right\| \\
\quad \leq\|(\gamma f+(I-A)) x-(\gamma f+(I-A)) y\| \\
\quad \leq \gamma\|f(x)-f(y)\|+\|I-A\|\|x-y\| \\
\quad \leq \gamma l\|x-y\|+(1-\bar{\gamma})\|x-y\| \\
\quad=(1-(\bar{\gamma}-\gamma l))\|x-y\| .
\end{aligned}
$$


By the Banach contraction principle, we deduce that $P_{\Omega}(\gamma f+(I-A))$ has a unique fixed point $x^{*} \in H$. That is, $x^{*}=P_{\Omega}(\gamma f+(I-A)) x^{*}$. In addition, by Proposition 2.2 we have $u_{n}=T_{r_{n}}^{(F, \varphi)} x_{n}$ for all $n \geq 1$.

We divide the rest of the proof into several steps.

Step 1. We show that $\left\{x_{n}\right\}$ is bounded. Indeed, take $p \in \Omega$ arbitrarily. Since $p=T_{r_{n}}^{(F, \varphi)} p$ and $p=G p=P_{C}\left(I-\mu_{1} B_{1}\right) P_{C}\left(I-\mu_{2} B_{2}\right) p, B_{i}$ is $\zeta_{i}$-inverse-strongly monotone for $i=1,2$, by Proposition 2.2(c) we deduce from $0 \leq \mu_{i} \leq 2 \zeta_{i}, i=1,2$, that for any $n \geq 1$,

$$
\begin{aligned}
\left\|G u_{n}-p\right\|^{2}= & \left\|P_{C}\left(I-\mu_{1} B_{1}\right) P_{C}\left(I-\mu_{2} B_{2}\right) u_{n}-P_{C}\left(I-\mu_{1} B_{1}\right) P_{C}\left(I-\mu_{2} B_{2}\right) p\right\|^{2} \\
\leq & \left\|\left(I-\mu_{1} B_{1}\right) P_{C}\left(I-\mu_{2} B_{2}\right) u_{n}-\left(I-\mu_{1} B_{1}\right) P_{C}\left(I-\mu_{2} B_{2}\right) p\right\|^{2} \\
= & \|\left[P_{C}\left(I-\mu_{2} B_{2}\right) u_{n}-P_{C}\left(I-\mu_{2} B_{2}\right) p\right] \\
& -\mu_{1}\left[B_{1} P_{C}\left(I-\mu_{2} B_{2}\right) u_{n}-B_{1} P_{C}\left(I-\mu_{2} B_{2}\right) p\right] \|^{2} \\
\leq & \left\|P_{C}\left(I-\mu_{2} B_{2}\right) u_{n}-P_{C}\left(I-\mu_{2} B_{2}\right) p\right\|^{2} \\
& +\mu_{1}\left(\mu_{1}-2 \zeta_{1}\right)\left\|B_{1} P_{C}\left(I-\mu_{2} B_{2}\right) u_{n}-B_{1} P_{C}\left(I-\mu_{2} B_{2}\right) p\right\|^{2} \\
\leq & \left\|P_{C}\left(I-\mu_{2} B_{2}\right) u_{n}-P_{C}\left(I-\mu_{2} B_{2}\right) p\right\|^{2} \\
\leq & \left\|\left(I-\mu_{2} B_{2}\right) u_{n}-\left(I-\mu_{2} B_{2}\right) p\right\|^{2} \\
= & \left\|\left(u_{n}-p\right)-\mu_{2}\left(B_{2} u_{n}-B_{2} p\right)\right\|^{2} \\
\leq & \left\|u_{n}-p\right\|^{2}+\mu_{2}\left(\mu_{2}-2 \zeta_{2}\right)\left\|B_{2} u_{n}-B_{2} p\right\|^{2} \\
\leq & \left\|u_{n}-p\right\|^{2}=\left\|T_{r_{n}}^{(F, \varphi)} x_{n}-T_{r_{n}}^{(F, \varphi)} p\right\|^{2} \leq\left\|x_{n}-p\right\|^{2} .
\end{aligned}
$$

(This shows that $G$ is nonexpansive.) Thus, from (3.1), (3.4) and $W_{n} p=p$, we get

$$
\begin{aligned}
\left\|x_{n+1}-p\right\| & =\left\|P_{C}\left[\alpha_{n} \gamma f\left(x_{n}\right)+\beta_{n} x_{n}+\left(\left(1-\beta_{n}\right) I-\alpha_{n} A\right) W_{n} G u_{n}\right]-p\right\| \\
& \leq\left\|\alpha_{n} \gamma f\left(x_{n}\right)+\beta_{n} x_{n}+\left(\left(1-\beta_{n}\right) I-\alpha_{n} A\right) W_{n} G u_{n}-p\right\| \\
& =\left\|\alpha_{n}\left(\gamma f\left(x_{n}\right)-A p\right)+\beta_{n}\left(x_{n}-p\right)+\left(\left(1-\beta_{n}\right) I-\alpha_{n} A\right)\left(W_{n} G u_{n}-p\right)\right\| \\
& \leq\left\|\left(1-\beta_{n}\right) I-\alpha_{n} A\right\|\left\|W_{n} G u_{n}-p\right\|+\beta_{n}\left\|x_{n}-p\right\|+\alpha_{n}\left\|\gamma f\left(x_{n}\right)-A p\right\| \\
& \leq\left(1-\beta_{n}-\alpha_{n} \bar{\gamma}\right)\left\|G u_{n}-p\right\|+\beta_{n}\left\|x_{n}-p\right\|+\alpha_{n}\left\|\gamma f\left(x_{n}\right)-A p\right\| \\
& \leq\left(1-\alpha_{n} \bar{\gamma}\right)\left\|x_{n}-p\right\|+\alpha_{n}\left(\gamma\left\|f\left(x_{n}\right)-f(p)\right\|+\|\gamma f(p)-A p\|\right) \\
& \leq\left(1-\alpha_{n} \bar{\gamma}\right)\left\|x_{n}-p\right\|+\alpha_{n}\left(\gamma l\left\|x_{n}-p\right\|+\|\gamma f(p)-A p\|\right) \\
& =\left[1-(\bar{\gamma}-\gamma l) \alpha_{n}\right]\left\|x_{n}-p\right\|+\alpha_{n}\|\gamma f(p)-A p\| \\
& =\left[1-(\bar{\gamma}-\gamma l) \alpha_{n}\right]\left\|x_{n}-p\right\|+(\bar{\gamma}-\gamma l) \alpha_{n} \frac{\|\gamma f(p)-A p\|}{\bar{\gamma}-\gamma l} \\
& \leq \max \left\{\left\|x_{n}-p\right\|, \frac{\|\gamma f(p)-A p\|}{\bar{\gamma}-\gamma l}\right\} .
\end{aligned}
$$

By induction, we get

$$
\left\|x_{n}-p\right\| \leq \max \left\{\left\|x_{0}-p\right\|, \frac{\|\gamma f(p)-A p\|}{\bar{\gamma}-\gamma l}\right\} .
$$

Therefore, $\left\{x_{n}\right\}$ is bounded and so are the sequences $\left\{u_{n}\right\},\left\{f\left(x_{n}\right)\right\}$ and $\left\{W_{n} G u_{n}\right\}$. 
Step 2. We show that $\left\|x_{n+1}-x_{n}\right\| \rightarrow 0$ as $n \rightarrow \infty$. Indeed, we write $y_{n}=\alpha_{n} \gamma f\left(x_{n}\right)+\beta_{n} x_{n}+$ $\left(\left(1-\beta_{n}\right) I-\alpha_{n} A\right) W_{n} G u_{n}$. Then $x_{n+1}=P_{C} y_{n}$ for each $n \geq 1$. Define $y_{n}=\beta_{n} x_{n}+\left(1-\beta_{n}\right) w_{n}$ for each $n \geq 1$. Then from the definition of $w_{n}$, we obtain

$$
\begin{aligned}
w_{n+1}-w_{n}= & \frac{y_{n+1}-\beta_{n+1} x_{n+1}}{1-\beta_{n+1}}-\frac{y_{n}-\beta_{n} x_{n}}{1-\beta_{n}} \\
= & \frac{\alpha_{n+1} \gamma f\left(x_{n+1}\right)+\left(\left(1-\beta_{n+1}\right) I-\alpha_{n+1} A\right) W_{n+1} G u_{n+1}}{1-\beta_{n+1}} \\
& -\frac{\alpha_{n} \gamma f\left(x_{n}\right)+\left(\left(1-\beta_{n}\right) I-\alpha_{n} A\right) W_{n} G u_{n}}{1-\beta_{n}} \\
= & \gamma\left(\frac{\alpha_{n+1}}{1-\beta_{n+1}} f\left(x_{n+1}\right)-\frac{\alpha_{n}}{1-\beta_{n}} f\left(x_{n}\right)\right) \\
& +\left(I-\frac{\alpha_{n+1} A}{1-\beta_{n+1}}\right) W_{n+1} G u_{n+1}-\left(I-\frac{\alpha_{n} A}{1-\beta_{n}}\right) W_{n} G u_{n} \\
= & \gamma\left(\left(\frac{\alpha_{n+1}}{1-\beta_{n+1}}-\frac{\alpha_{n}}{1-\beta_{n}}\right) f\left(x_{n+1}\right)+\frac{\alpha_{n}}{1-\beta_{n}}\left(f\left(x_{n+1}\right)-f\left(x_{n}\right)\right)\right] \\
& +\left(\left(I-\frac{\alpha_{n+1} A}{1-\beta_{n+1}}\right)-\left(I-\frac{\alpha_{n} A}{1-\beta_{n}}\right)\right) W_{n+1} G u_{n+1} \\
& +\left(I-\frac{\alpha_{n} A}{1-\beta_{n}}\right)\left(W_{n+1} G u_{n+1}-W_{n} G u_{n}\right) \\
= & \left(\frac{\alpha_{n+1}}{1-\beta_{n+1}}-\frac{\alpha_{n}}{1-\beta_{n}}\right)\left(\gamma f\left(x_{n+1}\right)-A W_{n+1} G u_{n+1}\right)+\frac{\alpha_{n}}{1-\beta_{n}} \gamma\left(f\left(x_{n+1}\right)-f\left(x_{n}\right)\right) \\
& +\left(I-\frac{\alpha_{n}}{1-\beta_{n}} A\right)\left(W_{n+1} G u_{n+1}-W_{n} G u_{n}\right) .
\end{aligned}
$$

It follows from Lemma 2.7 that

$$
\begin{aligned}
\left\|w_{n+1}-w_{n}\right\| \leq & \left|\frac{\alpha_{n+1}}{1-\beta_{n+1}}-\frac{\alpha_{n}}{1-\beta_{n}}\right|\left\|\gamma f\left(x_{n+1}\right)-A W_{n+1} G u_{n+1}\right\| \\
& +\frac{\alpha_{n}}{1-\beta_{n}} \gamma\left\|f\left(x_{n+1}\right)-f\left(x_{n}\right)\right\|+\left\|\left(I-\frac{\alpha_{n}}{1-\beta_{n}} A\right)\left(W_{n+1} G u_{n+1}-W_{n} G u_{n}\right)\right\| \\
\leq & \left|\frac{\alpha_{n+1}}{1-\beta_{n+1}}-\frac{\alpha_{n}}{1-\beta_{n}}\right|\left\|\gamma f\left(x_{n+1}\right)-A W_{n+1} G u_{n+1}\right\|+\frac{\alpha_{n}}{1-\beta_{n}} \gamma l\left\|x_{n+1}-x_{n}\right\| \\
& +\left\|I-\frac{\alpha_{n}}{1-\beta_{n}} A\right\|\left\|W_{n+1} G u_{n+1}-W_{n} G u_{n}\right\| \\
\leq & \left|\frac{\left(\alpha_{n+1}-\alpha_{n}\right)\left(1-\beta_{n}\right)+\alpha_{n}\left(\beta_{n+1}-\beta_{n}\right)}{\left(1-\beta_{n}\right)\left(1-\beta_{n+1}\right)}\right|\left\|\gamma f\left(x_{n+1}\right)-A W_{n+1} G u_{n+1}\right\| \\
& +\frac{\alpha_{n}}{1-\beta_{n}} \gamma l\left\|x_{n+1}-x_{n}\right\| \\
& +\left\|I-\frac{\alpha_{n}}{1-\beta_{n}} A\right\|\left(\left\|W_{n+1} G u_{n+1}-W_{n+1} G u_{n}\right\|+\left\|W_{n+1} G u_{n}-W_{n} G u_{n}\right\|\right) \\
\leq & \frac{\left|\alpha_{n+1}-\alpha_{n}\right|+\left|\beta_{n+1}-\beta_{n}\right|}{(1-d)\left(1-\beta_{n}\right)}\left\|\gamma f\left(x_{n+1}\right)-A W_{n+1} G u_{n+1}\right\| \\
& +\frac{\alpha_{n}}{1-\beta_{n}} \gamma l\left\|x_{n+1}-x_{n}\right\|
\end{aligned}
$$




$$
\begin{aligned}
& +\left(1-\frac{\alpha_{n}}{1-\beta_{n}} \bar{\gamma}\right)\left(\left\|G u_{n+1}-G u_{n}\right\|+\left\|W_{n+1} G u_{n}-W_{n} G u_{n}\right\|\right) \\
\leq & \frac{\left|\alpha_{n+1}-\alpha_{n}\right|+\left|\beta_{n+1}-\beta_{n}\right|}{(1-d)\left(1-\beta_{n}\right)}\left\|\gamma f\left(x_{n+1}\right)-A W_{n+1} G u_{n+1}\right\| \\
& +\frac{\alpha_{n}}{1-\beta_{n}} \gamma l\left\|x_{n+1}-x_{n}\right\| \\
& +\left(1-\frac{\alpha_{n}}{1-\beta_{n}} \bar{\gamma}\right)\left(\left\|u_{n+1}-u_{n}\right\|+\left\|W_{n+1} G u_{n}-W_{n} G u_{n}\right\|\right) .
\end{aligned}
$$

From (1.13), since $W_{n}, T_{n}$ and $U_{n, i}$ are all nonexpansive, we have

$$
\begin{aligned}
\left\|W_{n+1} G u_{n}-W_{n} G u_{n}\right\| & =\left\|\lambda_{1} T_{1} U_{n+1,2} G u_{n}-\lambda_{1} T_{1} U_{n, 2} G u_{n}\right\| \\
& \leq \lambda_{1}\left\|U_{n+1,2} G u_{n}-U_{n, 2} G u_{n}\right\| \\
& =\lambda_{1}\left\|\lambda_{2} T_{2} U_{n+1,3} G u_{n}-\lambda_{2} T_{2} U_{n, 3} G u_{n}\right\| \\
& \leq \lambda_{1} \lambda_{2}\left\|U_{n+1,3} G u_{n}-U_{n, 3} G u_{n}\right\| \\
& \leq \cdots \\
& \leq \lambda_{1} \lambda_{2} \cdots \lambda_{n}\left\|U_{n+1, n+1} G u_{n}-U_{n, n+1} G u_{n}\right\| \\
& \leq M \prod_{i=1}^{n} \lambda_{i},
\end{aligned}
$$

where $\sup _{n \geq 1}\left\{\left\|U_{n+1, n+1} G u_{n}\right\|+\left\|U_{n, n+1} G u_{n}\right\|\right\} \leq M$ for some $M>0$. Furthermore, we estimate $\left\|u_{n+1}-u_{n}\right\|$. Taking into account that $0<\liminf _{n \rightarrow \infty} \beta_{n} \leq \limsup _{n \rightarrow \infty} \beta_{n}<1$ and $\liminf _{n \rightarrow \infty} r_{n}>0$, we may assume, without loss of generality, that $\left\{\beta_{n}\right\} \subset[c, d] \subset(0,1)$ and $\left\{r_{n}\right\} \subset[\epsilon, \infty)$ for some $\epsilon>0$. Utilizing Remark 2.1, we get

$$
\begin{aligned}
\left\|u_{n+1}-u_{n}\right\| & =\left\|T_{r_{n+1}}^{(F, \varphi)} x_{n+1}-T_{r_{n}}^{(F, \varphi)} x_{n}\right\| \\
& \leq\left\|T_{r_{n+1}}^{(F, \varphi)} x_{n+1}-T_{r_{n+1}}^{(F, \varphi)} x_{n}\right\|+\left\|T_{r_{n+1}}^{(F, \varphi)} x_{n}-T_{r_{n}}^{(F, \varphi)} x_{n}\right\| \\
& \leq\left\|x_{n+1}-x_{n}\right\|+\frac{\left|r_{n+1}-r_{n}\right|}{r_{n+1}}\left\|T_{r_{n+1}}^{(F, \varphi)} x_{n}-x_{n}\right\| \\
& \leq\left\|x_{n+1}-x_{n}\right\|+\frac{\left|r_{n+1}-r_{n}\right|}{\epsilon}\left\|T_{r_{n+1}}^{(F, \varphi)} x_{n}-x_{n}\right\| \\
& \leq\left\|x_{n+1}-x_{n}\right\|+M_{1}\left|r_{n+1}-r_{n}\right|
\end{aligned}
$$

where $\sup _{n \geq 1}\left\{\frac{1}{\epsilon}\left\|T_{r_{n+1}}^{(F, \varphi)} x_{n}-x_{n}\right\|\right\} \leq M_{1}$ for some $M_{1}>0$.

Note that

$$
y_{n+1}-y_{n}=\beta_{n}\left(x_{n+1}-x_{n}\right)+\left(\beta_{n+1}-\beta_{n}\right)\left(x_{n+1}-w_{n+1}\right)+\left(1-\beta_{n}\right)\left(w_{n+1}-w_{n}\right) .
$$

Hence it follows from (3.5)-(3.7) that

$$
\begin{aligned}
& \left\|x_{n+2}-x_{n+1}\right\| \\
& \quad=\left\|P_{C} y_{n+1}-P_{C} y_{n}\right\| \leq\left\|y_{n+1}-y_{n}\right\| \\
& \quad \leq \beta_{n}\left\|x_{n+1}-x_{n}\right\|+\left|\beta_{n+1}-\beta_{n}\right|\left\|x_{n+1}-w_{n+1}\right\|+\left(1-\beta_{n}\right)\left\|w_{n+1}-w_{n}\right\|
\end{aligned}
$$




$$
\begin{aligned}
& \leq \beta_{n}\left\|x_{n+1}-x_{n}\right\|+\left|\beta_{n+1}-\beta_{n}\right|\left\|x_{n+1}-w_{n+1}\right\| \\
& +\left(1-\beta_{n}\right)\left\{\frac{\left|\alpha_{n+1}-\alpha_{n}\right|+\left|\beta_{n+1}-\beta_{n}\right|}{(1-d)\left(1-\beta_{n}\right)}\left\|\gamma f\left(x_{n+1}\right)-A W_{n+1} G u_{n+1}\right\|\right. \\
& \left.+\frac{\alpha_{n}}{1-\beta_{n}} \gamma l\left\|x_{n+1}-x_{n}\right\|+\left(1-\frac{\alpha_{n}}{1-\beta_{n}} \bar{\gamma}\right)\left\|u_{n+1}-u_{n}\right\|+\left\|W_{n+1} G u_{n}-W_{n} G u_{n}\right\|\right\} \\
& \leq \beta_{n}\left\|x_{n+1}-x_{n}\right\|+\left|\beta_{n+1}-\beta_{n}\right|\left\|x_{n+1}-w_{n+1}\right\| \\
& +\left(1-\beta_{n}\right)\left\{\frac{\left|\alpha_{n+1}-\alpha_{n}\right|+\left|\beta_{n+1}-\beta_{n}\right|}{(1-d)\left(1-\beta_{n}\right)}\left\|\gamma f\left(x_{n+1}\right)-A W_{n+1} G u_{n+1}\right\|\right. \\
& +\frac{\alpha_{n}}{1-\beta_{n}} \gamma l\left\|x_{n+1}-x_{n}\right\|+\left(1-\frac{\alpha_{n}}{1-\beta_{n}} \bar{\gamma}\right)\left[\left\|x_{n+1}-x_{n}\right\|\right. \\
& \left.\left.+M_{1}\left|r_{n+1}-r_{n}\right|+\left\|W_{n+1} G u_{n}-W_{n} G u_{n}\right\|\right]\right\} \\
& \leq \beta_{n}\left\|x_{n+1}-x_{n}\right\|+\left|\beta_{n+1}-\beta_{n}\right|\left\|x_{n+1}-w_{n+1}\right\| \\
& +\left(1-\beta_{n}\right)\left\{\frac{\left|\alpha_{n+1}-\alpha_{n}\right|+\left|\beta_{n+1}-\beta_{n}\right|}{(1-d)\left(1-\beta_{n}\right)}\left\|\gamma f\left(x_{n+1}\right)-A W_{n+1} G u_{n+1}\right\|\right. \\
& \left.+\left(1-\frac{\alpha_{n}}{1-\beta_{n}}(\bar{\gamma}-\gamma l)\right)\left\|x_{n+1}-x_{n}\right\|+M_{1}\left|r_{n+1}-r_{n}\right|+\left\|W_{n+1} G u_{n}-W_{n} G u_{n}\right\|\right\} \\
& \leq \beta_{n}\left\|x_{n+1}-x_{n}\right\|+\left|\beta_{n+1}-\beta_{n}\right|\left\|x_{n+1}-w_{n+1}\right\| \\
& +\frac{\left|\alpha_{n+1}-\alpha_{n}\right|+\left|\beta_{n+1}-\beta_{n}\right|}{1-d}\left\|\gamma f\left(x_{n+1}\right)-A W_{n+1} G u_{n+1}\right\| \\
& +\left(1-\beta_{n}-\alpha_{n}(\bar{\gamma}-\gamma l)\right)\left\|x_{n+1}-x_{n}\right\|+M_{1}\left|r_{n+1}-r_{n}\right|+\left\|W_{n+1} G u_{n}-W_{n} G u_{n}\right\| \\
& \leq\left(1-\alpha_{n}(\bar{\gamma}-\gamma l)\right)\left\|x_{n+1}-x_{n}\right\|+\left|\beta_{n+1}-\beta_{n}\right|\left\|x_{n+1}-w_{n+1}\right\| \\
& +\frac{\left|\alpha_{n+1}-\alpha_{n}\right|+\left|\beta_{n+1}-\beta_{n}\right|}{1-d}\left\|\gamma f\left(x_{n+1}\right)-A W_{n+1} G u_{n+1}\right\| \\
& +M_{1}\left|r_{n+1}-r_{n}\right|+\left\|W_{n+1} G u_{n}-W_{n} G u_{n}\right\| \\
& \leq\left(1-\alpha_{n}(\bar{\gamma}-\gamma l)\right)\left\|x_{n+1}-x_{n}\right\|+\left|\beta_{n+1}-\beta_{n}\right|\left\|x_{n+1}-w_{n+1}\right\| \\
& +\frac{\left|\alpha_{n+1}-\alpha_{n}\right|+\left|\beta_{n+1}-\beta_{n}\right|}{1-d}\left\|\gamma f\left(x_{n+1}\right)-A W_{n+1} G u_{n+1}\right\|+M_{1}\left|r_{n+1}-r_{n}\right|+M \prod_{i=1}^{n} \lambda_{i} \\
& \leq\left(1-\alpha_{n}(\bar{\gamma}-\gamma l)\right)\left\|x_{n+1}-x_{n}\right\|+M_{2}\left(\left|\alpha_{n+1}-\alpha_{n}\right|+\left|\beta_{n+1}-\beta_{n}\right|+\left|r_{n+1}-r_{n}\right|+b^{n}\right)
\end{aligned}
$$

where $\sup _{n \geq 1}\left\{\frac{1}{1-d}\left\|\gamma f\left(x_{n}\right)-A W_{n} G u_{n}\right\|+\left\|x_{n}-w_{n}\right\|+M_{1}+M\right\} \leq M_{2}$ for some $M_{2}>0$. Since $\sum_{n=1}^{\infty} \alpha_{n}=\infty, \sum_{n=1}^{\infty}\left|\alpha_{n+1}-\alpha_{n}\right|<\infty, \sum_{n=1}^{\infty}\left|\beta_{n+1}-\beta_{n}\right|<\infty$ and $\sum_{n=1}^{\infty}\left|r_{n+1}-r_{n}\right|<\infty$, from $b \in(0,1)$ and Lemma 2.8 we conclude that

$$
\lim _{n \rightarrow \infty}\left\|x_{n+1}-x_{n}\right\|=0
$$

Step 3. We show that $\lim _{n \rightarrow \infty}\left\|u_{n}-G u_{n}\right\|=0$. Indeed, for simplicity, we write $\tilde{u}_{n}=P_{C}(I-$ $\left.\mu_{2} B_{2}\right) u_{n}, v_{n}=P_{C}\left(I-\mu_{1} B_{1}\right) \tilde{u}_{n}$ and $\tilde{p}=P_{C}\left(I-\mu_{2} B_{2}\right) p$. Then $v_{n}=G u_{n}$ and

$$
p=P_{C}\left(I-\mu_{1} B_{1}\right) \tilde{p}=P_{C}\left(I-\mu_{1} B_{1}\right) P_{C}\left(I-\mu_{2} B_{2}\right) p=G p .
$$


From (3.1), (3.4) and Proposition 2.1(i) and Lemma 2.2(b), we obtain that for $p \in \Omega$,

$$
\begin{aligned}
& \left\|x_{n+1}-p\right\|^{2} \\
& \leq\left\|\alpha_{n}\left(\gamma f\left(x_{n}\right)-A W_{n} G u_{n}\right)+\beta_{n}\left(x_{n}-p\right)+\left(1-\beta_{n}\right)\left(W_{n} G u_{n}-p\right)\right\|^{2} \\
& =\left\|\beta_{n}\left(x_{n}-p\right)+\left(1-\beta_{n}\right)\left(W_{n} G u_{n}-p\right)\right\|^{2} \\
& +2 \alpha_{n}\left\langle\left(\gamma f\left(x_{n}\right)-A W_{n} G u_{n}\right), \beta_{n}\left(x_{n}-p\right)+\left(1-\beta_{n}\right)\left(W_{n} G u_{n}-p\right)\right\rangle \\
& +\alpha_{n}^{2}\left\|\gamma f\left(x_{n}\right)-A W_{n} G u_{n}\right\|^{2} \\
& \leq \beta_{n}\left\|x_{n}-p\right\|^{2}+\left(1-\beta_{n}\right)\left\|W_{n} G u_{n}-p\right\|^{2}-\beta_{n}\left(1-\beta_{n}\right)\left\|x_{n}-W_{n} G u_{n}\right\|^{2} \\
& +\alpha_{n}\left\|\gamma f\left(x_{n}\right)-A W_{n} G u_{n}\right\|\left[2\left\|\beta_{n}\left(x_{n}-p\right)+\left(1-\beta_{n}\right)\left(W_{n} G u_{n}-p\right)\right\|\right. \\
& \left.+\alpha_{n}\left\|\gamma f\left(x_{n}\right)-A W_{n} G u_{n}\right\|\right] \\
& \leq \beta_{n}\left\|x_{n}-p\right\|^{2}+\left(1-\beta_{n}\right)\left\|G u_{n}-p\right\|^{2}-\beta_{n}\left(1-\beta_{n}\right)\left\|x_{n}-W_{n} G u_{n}\right\|^{2} \\
& +\alpha_{n}\left\|\gamma f\left(x_{n}\right)-A W_{n} G u_{n}\right\|\left[2\left(\beta_{n}\left\|x_{n}-p\right\|+\left(1-\beta_{n}\right)\left\|u_{n}-p\right\|\right)\right. \\
& \left.+\alpha_{n}\left\|\gamma f\left(x_{n}\right)-A W_{n} G u_{n}\right\|\right] \\
& \leq \beta_{n}\left\|x_{n}-p\right\|^{2}+\left(1-\beta_{n}\right)\left\|G u_{n}-p\right\|^{2}-\beta_{n}\left(1-\beta_{n}\right)\left\|x_{n}-W_{n} G u_{n}\right\|^{2} \\
& +\alpha_{n}\left\|\gamma f\left(x_{n}\right)-A W_{n} G u_{n}\right\|\left(2\left\|x_{n}-p\right\|+\alpha_{n}\left\|\gamma f\left(x_{n}\right)-A W_{n} G u_{n}\right\|\right) \\
& \leq \beta_{n}\left\|x_{n}-p\right\|^{2}+\left(1-\beta_{n}\right)\left[\left\|u_{n}-p\right\|^{2}+\mu_{2}\left(\mu_{2}-2 \zeta_{2}\right)\left\|B_{2} u_{n}-B_{2} p\right\|^{2}\right. \\
& \left.+\mu_{1}\left(\mu_{1}-2 \zeta_{1}\right)\left\|B_{1} \tilde{u}_{n}-B_{1} \tilde{p}\right\|^{2}\right]-\beta_{n}\left(1-\beta_{n}\right)\left\|x_{n}-W_{n} G u_{n}\right\|^{2} \\
& +\alpha_{n}\left\|\gamma f\left(x_{n}\right)-A W_{n} G u_{n}\right\|\left(2\left\|x_{n}-p\right\|+\alpha_{n}\left\|\gamma f\left(x_{n}\right)-A W_{n} G u_{n}\right\|\right) \\
& \leq \beta_{n}\left\|x_{n}-p\right\|^{2}+\left(1-\beta_{n}\right)\left[\left\|x_{n}-p\right\|^{2}+\mu_{2}\left(\mu_{2}-2 \zeta_{2}\right)\left\|B_{2} u_{n}-B_{2} p\right\|^{2}\right. \\
& \left.+\mu_{1}\left(\mu_{1}-2 \zeta_{1}\right)\left\|B_{1} \tilde{u}_{n}-B_{1} \tilde{p}\right\|^{2}\right]-\beta_{n}\left(1-\beta_{n}\right)\left\|x_{n}-W_{n} G u_{n}\right\|^{2} \\
& +\alpha_{n}\left\|\gamma f\left(x_{n}\right)-A W_{n} G u_{n}\right\|\left(2\left\|x_{n}-p\right\|+\alpha_{n}\left\|\gamma f\left(x_{n}\right)-A W_{n} G u_{n}\right\|\right) \\
& =\left\|x_{n}-p\right\|^{2}-\left(1-\beta_{n}\right)\left[\mu_{2}\left(2 \zeta_{2}-\mu_{2}\right)\left\|B_{2} u_{n}-B_{2} p\right\|^{2}\right. \\
& \left.+\mu_{1}\left(2 \zeta_{1}-\mu_{1}\right)\left\|B_{1} \tilde{u}_{n}-B_{1} \tilde{p}\right\|^{2}\right]-\beta_{n}\left(1-\beta_{n}\right)\left\|x_{n}-W_{n} G u_{n}\right\|^{2} \\
& +\alpha_{n}\left\|\gamma f\left(x_{n}\right)-A W_{n} G u_{n}\right\|\left(2\left\|x_{n}-p\right\|+\alpha_{n}\left\|\gamma f\left(x_{n}\right)-A W_{n} G u_{n}\right\|\right),
\end{aligned}
$$

which immediately implies that

$$
\begin{aligned}
(1-d) & {\left[\mu_{2}\left(2 \zeta_{2}-\mu_{2}\right)\left\|B_{2} u_{n}-B_{2} p\right\|^{2}+\mu_{1}\left(2 \zeta_{1}-\mu_{1}\right)\left\|B_{1} \tilde{u}_{n}-B_{1} \tilde{p}\right\|^{2}\right] } \\
& +c(1-d)\left\|x_{n}-W_{n} G u_{n}\right\| \\
\leq & \left(1-\beta_{n}\right)\left[\mu_{2}\left(2 \zeta_{2}-\mu_{2}\right)\left\|B_{2} u_{n}-B_{2} p\right\|^{2}+\mu_{1}\left(2 \zeta_{1}-\mu_{1}\right)\left\|B_{1} \tilde{u}_{n}-B_{1} \tilde{p}\right\|^{2}\right] \\
& +\beta_{n}\left(1-\beta_{n}\right)\left\|x_{n}-W_{n} G u_{n}\right\| \\
\leq & \left\|x_{n}-p\right\|^{2}-\left\|x_{n+1}-p\right\|^{2} \\
& +\alpha_{n}\left\|\gamma f\left(x_{n}\right)-A W_{n} G u_{n}\right\|\left(2\left\|x_{n}-p\right\|+\alpha_{n}\left\|\gamma f\left(x_{n}\right)-A W_{n} G u_{n}\right\|\right) \\
\leq & \left\|x_{n}-x_{n+1}\right\|\left(\left\|x_{n}-p\right\|+\left\|x_{n+1}-p\right\|\right) \\
& +\alpha_{n}\left\|\gamma f\left(x_{n}\right)-A W_{n} G u_{n}\right\|\left(2\left\|x_{n}-p\right\|+\alpha_{n}\left\|\gamma f\left(x_{n}\right)-A W_{n} G u_{n}\right\|\right) .
\end{aligned}
$$


Since $\lim _{n \rightarrow \infty} \alpha_{n}=0, \lim _{n \rightarrow \infty}\left\|x_{n+1}-x_{n}\right\|=0$ and $\mu_{i} \in\left(0,2 \zeta_{i}\right), i=1,2$, we deduce from the boundedness of $\left\{x_{n}\right\},\left\{f\left(x_{n}\right)\right\}$ and $\left\{W_{n} G u_{n}\right\}$ that

$$
\begin{aligned}
& \lim _{n \rightarrow \infty}\left\|B_{2} u_{n}-B_{2} p\right\|=0, \quad \lim _{n \rightarrow \infty}\left\|B_{1} \tilde{u}_{n}-B_{1} \tilde{p}\right\|=0 \quad \text { and } \\
& \lim _{n \rightarrow \infty}\left\|x_{n}-W_{n} G u_{n}\right\|=0 .
\end{aligned}
$$

Also, in terms of the firm nonexpansivity of $P_{C}$ and the $\zeta_{i}$-inverse strong monotonicity of $B_{i}$ for $i=1,2$, we obtain from $\mu_{i} \in\left(0,2 \zeta_{i}\right), i \in\{1,2\}$ and (3.4) that

$$
\begin{aligned}
\left\|\tilde{u}_{n}-\tilde{p}\right\|^{2}= & \left\|P_{C}\left(I-\mu_{2} B_{2}\right) u_{n}-P_{C}\left(I-\mu_{2} B_{2}\right) p\right\|^{2} \\
\leq & \left\langle\left(I-\mu_{2} B_{2}\right) u_{n}-\left(I-\mu_{2} B_{2}\right) p, \tilde{u}_{n}-\tilde{p}\right\rangle \\
= & \frac{1}{2}\left[\left\|\left(I-\mu_{2} B_{2}\right) u_{n}-\left(I-\mu_{2} B_{2}\right) p\right\|^{2}+\left\|\tilde{u}_{n}-\tilde{p}\right\|^{2}\right. \\
& \left.-\left\|\left(I-\mu_{2} B_{2}\right) u_{n}-\left(I-\mu_{2} B_{2}\right) p-\left(\tilde{u}_{n}-\tilde{p}\right)\right\|^{2}\right] \\
\leq & \frac{1}{2}\left[\left\|u_{n}-p\right\|^{2}+\left\|\tilde{u}_{n}-\tilde{p}\right\|^{2}-\left\|\left(u_{n}-\tilde{u}_{n}\right)-\mu_{2}\left(B_{2} u_{n}-B_{2} p\right)-(p-\tilde{p})\right\|^{2}\right] \\
\leq & \frac{1}{2}\left[\left\|x_{n}-p\right\|^{2}+\left\|\tilde{u}_{n}-\tilde{p}\right\|^{2}-\left\|\left(u_{n}-\tilde{u}_{n}\right)-(p-\tilde{p})\right\|^{2}\right. \\
& \left.+2 \mu_{2}\left\langle\left(u_{n}-\tilde{u}_{n}\right)-(p-\tilde{p}), B_{2} u_{n}-B_{2} p\right\rangle-\mu_{2}^{2}\left\|B_{2} u_{n}-B_{2} p\right\|^{2}\right]
\end{aligned}
$$

and

$$
\begin{aligned}
\left\|v_{n}-p\right\|^{2}= & \left\|P_{C}\left(I-\mu_{1} B_{1}\right) \tilde{u}_{n}-P_{C}\left(I-\mu_{1} B_{1}\right) \tilde{p}\right\|^{2} \\
\leq & \left\langle\left(I-\mu_{1} B_{1}\right) v_{n}-\left(I-\mu_{1} B_{1}\right) \tilde{p}, v_{n}-p\right\rangle \\
= & \frac{1}{2}\left[\left\|\left(I-\mu_{1} B_{1}\right) \tilde{u}_{n}-\left(I-\mu_{1} B_{1}\right) \tilde{p}\right\|^{2}+\left\|v_{n}-p\right\|^{2}\right. \\
& \left.-\left\|\left(I-\mu_{1} B_{1}\right) \tilde{u}_{n}-\left(I-\mu_{1} B_{1}\right) \tilde{p}-\left(v_{n}-p\right)\right\|^{2}\right] \\
\leq & \frac{1}{2}\left[\left\|\tilde{u}_{n}-\tilde{p}\right\|^{2}+\left\|v_{n}-p\right\|^{2}-\left\|\left(\tilde{u}_{n}-v_{n}\right)+(p-\tilde{p})\right\|^{2}\right. \\
& \left.+2 \mu_{1}\left\langle B_{1} \tilde{u}_{n}-B_{1} \tilde{p},\left(\tilde{u}_{n}-v_{n}\right)+(p-\tilde{p})\right\rangle-\mu_{1}^{2}\left\|B_{1} \tilde{u}_{n}-B_{1} \tilde{p}\right\|^{2}\right] \\
\leq & \frac{1}{2}\left[\left\|x_{n}-p\right\|^{2}+\left\|v_{n}-p\right\|^{2}-\left\|\left(\tilde{u}_{n}-v_{n}\right)+(p-\tilde{p})\right\|^{2}\right. \\
& \left.+2 \mu_{1}\left\langle B_{1} \tilde{u}_{n}-B_{1} \tilde{p},\left(\tilde{u}_{n}-v_{n}\right)+(p-\tilde{p})\right\rangle\right] .
\end{aligned}
$$

Thus, we have

$$
\begin{aligned}
\left\|\tilde{u}_{n}-\tilde{p}\right\|^{2} \leq & \left\|x_{n}-p\right\|^{2}-\left\|\left(u_{n}-\tilde{u}_{n}\right)-(p-\tilde{p})\right\|^{2} \\
& +2 \mu_{2}\left\langle\left(u_{n}-\tilde{u}_{n}\right)-(p-\tilde{p}), B_{2} u_{n}-B_{2} p\right\rangle-\mu_{2}^{2}\left\|B_{2} u_{n}-B_{2} p\right\|^{2}
\end{aligned}
$$

and

$$
\begin{aligned}
\left\|v_{n}-p\right\|^{2} \leq & \left\|x_{n}-p\right\|^{2}-\left\|\left(\tilde{u}_{n}-v_{n}\right)+(p-\tilde{p})\right\|^{2} \\
& +2 \mu_{1}\left\|B_{1} \tilde{u}_{n}-B_{1} \tilde{p}\right\|\left\|\left(\tilde{u}_{n}-v_{n}\right)+(p-\tilde{p})\right\| .
\end{aligned}
$$


Consequently, from (3.4), (3.9) and (3.11) it follows that

$$
\begin{aligned}
&\left\|x_{n+1}-p\right\|^{2} \\
& \leq \beta_{n}\left\|x_{n}-p\right\|+\left(1-\beta_{n}\right)\left\|G u_{n}-p\right\|^{2}-\beta_{n}\left(1-\beta_{n}\right)\left\|x_{n}-W_{n} G u_{n}\right\| \\
&+\alpha_{n}\left\|\gamma f\left(x_{n}\right)-A W_{n} G u_{n}\right\|\left(2\left\|x_{n}-p\right\|+\alpha_{n}\left\|\gamma f\left(x_{n}\right)-A W_{n} G u_{n}\right\|\right) \\
& \leq \beta_{n}\left\|x_{n}-p\right\|+\left(1-\beta_{n}\right)\left\|\tilde{u}_{n}-\tilde{p}\right\|^{2} \\
&+\alpha_{n}\left\|\gamma f\left(x_{n}\right)-A W_{n} G u_{n}\right\|\left(2\left\|x_{n}-p\right\|+\alpha_{n}\left\|\gamma f\left(x_{n}\right)-A W_{n} G u_{n}\right\|\right) \\
& \leq \beta_{n}\left\|x_{n}-p\right\|+\left(1-\beta_{n}\right)\left[\left\|x_{n}-p\right\|^{2}-\left\|\left(u_{n}-\tilde{u}_{n}\right)-(p-\tilde{p})\right\|^{2}\right. \\
&\left.+2 \mu_{2}\left\|\left(u_{n}-\tilde{u}_{n}\right)-(p-\tilde{p})\right\|\left\|B_{2} u_{n}-B_{2} p\right\|\right] \\
&+\alpha_{n}\left\|\gamma f\left(x_{n}\right)-A W_{n} G u_{n}\right\|\left(2\left\|x_{n}-p\right\|+\alpha_{n}\left\|\gamma f\left(x_{n}\right)-A W_{n} G u_{n}\right\|\right) \\
& \leq\left\|x_{n}-p\right\|^{2}-\left(1-\beta_{n}\right)\left\|\left(u_{n}-\tilde{u}_{n}\right)-(p-\tilde{p})\right\|^{2} \\
&+2 \mu_{2}\left\|\left(u_{n}-\tilde{u}_{n}\right)-(p-\tilde{p})\right\|\left\|B_{2} u_{n}-B_{2} p\right\| \\
&+\alpha_{n}\left\|\gamma f\left(x_{n}\right)-A W_{n} G u_{n}\right\|\left(2\left\|x_{n}-p\right\|+\alpha_{n}\left\|\gamma f\left(x_{n}\right)-A W_{n} G u_{n}\right\|\right),
\end{aligned}
$$

which yields

$$
\begin{aligned}
&(1-d)\left\|\left(u_{n}-\tilde{u}_{n}\right)-(p-\tilde{p})\right\|^{2} \\
& \leq\left(1-\beta_{n}\right)\left\|\left(u_{n}-\tilde{u}_{n}\right)-(p-\tilde{p})\right\|^{2} \\
& \leq\left\|x_{n}-p\right\|^{2}-\left\|x_{n+1}-p\right\|^{2}+2 \mu_{2}\left\|\left(u_{n}-\tilde{u}_{n}\right)-(p-\tilde{p})\right\|\left\|B_{2} u_{n}-B_{2} p\right\| \\
&+\alpha_{n}\left\|\gamma f\left(x_{n}\right)-A W_{n} G u_{n}\right\|\left(2\left\|x_{n}-p\right\|+\alpha_{n}\left\|\gamma f\left(x_{n}\right)-A W_{n} G u_{n}\right\|\right) \\
& \leq\left\|x_{n}-x_{n+1}\right\|\left(\left\|x_{n}-p\right\|+\left\|x_{n+1}-p\right\|\right)+2 \mu_{2}\left\|\left(u_{n}-\tilde{u}_{n}\right)-(p-\tilde{p})\right\|\left\|B_{2} u_{n}-B_{2} p\right\| \\
&+\alpha_{n}\left\|\gamma f\left(x_{n}\right)-A W_{n} G u_{n}\right\|\left(2\left\|x_{n}-p\right\|+\alpha_{n}\left\|\gamma f\left(x_{n}\right)-A W_{n} G u_{n}\right\|\right) .
\end{aligned}
$$

Since $\lim _{n \rightarrow \infty} \alpha_{n}=0, \lim _{n \rightarrow \infty}\left\|x_{n+1}-x_{n}\right\|=0$ and $\lim _{n \rightarrow \infty}\left\|B_{2} u_{n}-B_{2} p\right\|=0$, we deduce from the boundedness of $\left\{x_{n}\right\},\left\{u_{n}\right\},\left\{\tilde{u}_{n}\right\},\left\{f\left(x_{n}\right)\right\}$ and $\left\{W_{n} G u_{n}\right\}$ that

$$
\lim _{n \rightarrow \infty}\left\|\left(u_{n}-\tilde{u}_{n}\right)-(p-\tilde{p})\right\|=0 .
$$

Furthermore, from (3.4), (3.9) and (3.12) it follows that

$$
\begin{aligned}
& \left\|x_{n+1}-p\right\|^{2} \\
& \leq \beta_{n}\left\|x_{n}-p\right\|+\left(1-\beta_{n}\right)\left\|G u_{n}-p\right\|^{2} \\
& \quad+\alpha_{n}\left\|\gamma f\left(x_{n}\right)-A W_{n} G u_{n}\right\|\left(2\left\|x_{n}-p\right\|+\alpha_{n}\left\|\gamma f\left(x_{n}\right)-A W_{n} G u_{n}\right\|\right) \\
& \leq \quad \beta_{n}\left\|x_{n}-p\right\|+\left(1-\beta_{n}\right)\left\|v_{n}-p\right\|^{2} \\
& \quad+\alpha_{n}\left\|\gamma f\left(x_{n}\right)-A W_{n} G u_{n}\right\|\left(2\left\|x_{n}-p\right\|+\alpha_{n}\left\|\gamma f\left(x_{n}\right)-A W_{n} G u_{n}\right\|\right) \\
& \leq \beta_{n}\left\|x_{n}-p\right\|+\left(1-\beta_{n}\right)\left[\left\|x_{n}-p\right\|^{2}-\left\|\left(\tilde{u}_{n}-v_{n}\right)+(p-\tilde{p})\right\|^{2}\right. \\
& \left.\quad+2 \mu_{1}\left\|B_{1} \tilde{u}_{n}-B_{1} \tilde{p}\right\|\left\|\left(\tilde{u}_{n}-v_{n}\right)+(p-\tilde{p})\right\|\right]
\end{aligned}
$$




$$
\begin{aligned}
& +\alpha_{n}\left\|\gamma f\left(x_{n}\right)-A W_{n} G u_{n}\right\|\left(2\left\|x_{n}-p\right\|+\alpha_{n}\left\|\gamma f\left(x_{n}\right)-A W_{n} G u_{n}\right\|\right) \\
\leq & \left\|x_{n}-p\right\|^{2}-\left(1-\beta_{n}\right)\left\|\left(\tilde{u}_{n}-v_{n}\right)+(p-\tilde{p})\right\|^{2}+2 \mu_{1}\left\|B_{1} \tilde{u}_{n}-B_{1} \tilde{p}\right\|\left\|\left(\tilde{u}_{n}-v_{n}\right)+(p-\tilde{p})\right\| \\
& +\alpha_{n}\left\|\gamma f\left(x_{n}\right)-A W_{n} G u_{n}\right\|\left(2\left\|x_{n}-p\right\|+\alpha_{n}\left\|\gamma f\left(x_{n}\right)-A W_{n} G u_{n}\right\|\right),
\end{aligned}
$$

which leads to

$$
\begin{aligned}
(1-d) & \left\|\left(\tilde{u}_{n}-v_{n}\right)+(p-\tilde{p})\right\|^{2} \\
\leq & \left(1-\beta_{n}\right)\left\|\left(\tilde{u}_{n}-v_{n}\right)+(p-\tilde{p})\right\|^{2} \\
\leq & \left\|x_{n}-p\right\|^{2}-\left\|x_{n+1}-p\right\|^{2}+2 \mu_{1}\left\|B_{1} \tilde{u}_{n}-B_{1} \tilde{p}\right\|\left\|\left(\tilde{u}_{n}-v_{n}\right)+(p-\tilde{p})\right\| \\
& \quad+\alpha_{n}\left\|\gamma f\left(x_{n}\right)-A W_{n} G u_{n}\right\|\left(2\left\|x_{n}-p\right\|+\alpha_{n}\left\|\gamma f\left(x_{n}\right)-A W_{n} G u_{n}\right\|\right) \\
\leq & \left\|x_{n}-x_{n+1}\right\|\left(\left\|x_{n}-p\right\|+\left\|x_{n+1}-p\right\|\right)+2 \mu_{1}\left\|B_{1} \tilde{u}_{n}-B_{1} \tilde{p}\right\|\left\|\left(\tilde{u}_{n}-v_{n}\right)+(p-\tilde{p})\right\| \\
& +\alpha_{n}\left\|\gamma f\left(x_{n}\right)-A W_{n} G u_{n}\right\|\left(2\left\|x_{n}-p\right\|+\alpha_{n}\left\|\gamma f\left(x_{n}\right)-A W_{n} G u_{n}\right\|\right) .
\end{aligned}
$$

Since $\lim _{n \rightarrow \infty} \alpha_{n}=0, \lim _{n \rightarrow \infty}\left\|x_{n+1}-x_{n}\right\|=0$ and $\lim _{n \rightarrow \infty}\left\|B_{1} \tilde{u}_{n}-B_{1} \tilde{p}\right\|=0$, we deduce from the boundedness of $\left\{x_{n}\right\},\left\{v_{n}\right\},\left\{\tilde{u}_{n}\right\},\left\{f\left(x_{n}\right)\right\}$ and $\left\{W_{n} G u_{n}\right\}$ that

$$
\lim _{n \rightarrow \infty}\left\|\left(\tilde{u}_{n}-v_{n}\right)+(p-\tilde{p})\right\|=0
$$

Note that

$$
\left\|u_{n}-v_{n}\right\| \leq\left\|\left(u_{n}-\tilde{u}_{n}\right)-(p-\tilde{p})\right\|+\left\|\left(\tilde{u}_{n}-v_{n}\right)+(p-\tilde{p})\right\| .
$$

Hence from (3.13) and (3.14) we get

$$
\lim _{n \rightarrow \infty}\left\|u_{n}-v_{n}\right\|=\lim _{n \rightarrow \infty}\left\|u_{n}-G u_{n}\right\|=0
$$

Step 4. We show that $\lim _{n \rightarrow \infty}\left\|u_{n}-x_{n}\right\|=0$ and $\lim _{n \rightarrow \infty}\left\|u_{n}-W u_{n}\right\|=0$. Indeed, by Proposition 2.2(c) we have

$$
\begin{aligned}
\left\|u_{n}-p\right\|^{2} & =\left\|T_{r_{n}}^{(F, \varphi)} x_{n}-T_{r_{n}}^{(F, \varphi)} p\right\|^{2} \\
& \leq\left\langle u_{n}-p, x_{n}-p\right\rangle \\
& =\frac{1}{2}\left[\left\|u_{n}-p\right\|^{2}+\left\|x_{n}-p\right\|^{2}-\left\|u_{n}-x_{n}\right\|^{2}\right] .
\end{aligned}
$$

That is,

$$
\left\|u_{n}-p\right\|^{2} \leq\left\|x_{n}-p\right\|^{2}-\left\|u_{n}-x_{n}\right\|^{2} .
$$

From (3.4), (3.9) and (3.16) it follows that

$$
\begin{aligned}
\left\|x_{n+1}-p\right\|^{2} \leq & \beta_{n}\left\|x_{n}-p\right\|+\left(1-\beta_{n}\right)\left\|G u_{n}-p\right\|^{2} \\
& +\alpha_{n}\left\|\gamma f\left(x_{n}\right)-A W_{n} G u_{n}\right\|\left(2\left\|x_{n}-p\right\|+\alpha_{n}\left\|\gamma f\left(x_{n}\right)-A W_{n} G u_{n}\right\|\right)
\end{aligned}
$$




$$
\begin{aligned}
\leq & \beta_{n}\left\|x_{n}-p\right\|+\left(1-\beta_{n}\right)\left\|u_{n}-p\right\|^{2} \\
& +\alpha_{n}\left\|\gamma f\left(x_{n}\right)-A W_{n} G u_{n}\right\|\left(2\left\|x_{n}-p\right\|+\alpha_{n}\left\|\gamma f\left(x_{n}\right)-A W_{n} G u_{n}\right\|\right) \\
\leq & \beta_{n}\left\|x_{n}-p\right\|+\left(1-\beta_{n}\right)\left[\left\|x_{n}-p\right\|^{2}-\left\|u_{n}-x_{n}\right\|^{2}\right] \\
& +\alpha_{n}\left\|\gamma f\left(x_{n}\right)-A W_{n} G u_{n}\right\|\left(2\left\|x_{n}-p\right\|+\alpha_{n}\left\|\gamma f\left(x_{n}\right)-A W_{n} G u_{n}\right\|\right) \\
= & \left\|x_{n}-p\right\|^{2}-\left(1-\beta_{n}\right)\left\|u_{n}-x_{n}\right\|^{2} \\
& +\alpha_{n}\left\|\gamma f\left(x_{n}\right)-A W_{n} G u_{n}\right\|\left(2\left\|x_{n}-p\right\|+\alpha_{n}\left\|\gamma f\left(x_{n}\right)-A W_{n} G u_{n}\right\|\right) .
\end{aligned}
$$

So, we get

$$
\begin{aligned}
(1-d)\left\|u_{n}-x_{n}\right\|^{2} \leq & \left(1-\beta_{n}\right)\left\|u_{n}-x_{n}\right\|^{2} \\
\leq & \left\|x_{n}-p\right\|^{2}-\left\|x_{n+1}-p\right\|^{2} \\
& +\alpha_{n}\left\|\gamma f\left(x_{n}\right)-A W_{n} G u_{n}\right\|\left(2\left\|x_{n}-p\right\|+\alpha_{n}\left\|\gamma f\left(x_{n}\right)-A W_{n} G u_{n}\right\|\right) \\
\leq & \left\|x_{n}-x_{n+1}\right\|\left(\left\|x_{n}-p\right\|+\left\|x_{n+1}-p\right\|\right) \\
& +\alpha_{n}\left\|\gamma f\left(x_{n}\right)-A W_{n} G u_{n}\right\|\left(2\left\|x_{n}-p\right\|+\alpha_{n}\left\|\gamma f\left(x_{n}\right)-A W_{n} G u_{n}\right\|\right) .
\end{aligned}
$$

Since $\lim _{n \rightarrow \infty} \alpha_{n}=0$ and $\lim _{n \rightarrow \infty}\left\|x_{n+1}-x_{n}\right\|=0$, we deduce from the boundedness of $\left\{x_{n}\right\}$, $\left\{f\left(x_{n}\right)\right\}$ and $\left\{W_{n} G u_{n}\right\}$ that

$$
\lim _{n \rightarrow \infty}\left\|u_{n}-x_{n}\right\|=0
$$

In the meantime, we observe that

$$
\left\|G u_{n}-W_{n} G u_{n}\right\| \leq\left\|G u_{n}-u_{n}\right\|+\left\|u_{n}-x_{n}\right\|+\left\|x_{n}-W_{n} G u_{n}\right\| .
$$

From (3.10), (3.15) and (3.17) it follows that

$$
\lim _{n \rightarrow \infty}\left\|G u_{n}-W_{n} G u_{n}\right\|=0
$$

Also, note that

$$
\begin{aligned}
\left\|u_{n}-W u_{n}\right\| & \leq\left\|u_{n}-G u_{n}\right\|+\left\|G u_{n}-W_{n} G u_{n}\right\|+\left\|W_{n} G u_{n}-W_{n} u_{n}\right\|+\left\|W_{n} u_{n}-W u_{n}\right\| \\
& \leq 2\left\|u_{n}-G u_{n}\right\|+\left\|G u_{n}-W_{n} G u_{n}\right\|+\left\|W_{n} u_{n}-W u_{n}\right\| .
\end{aligned}
$$

From (3.15), (3.18), Remark 2.3 and the boundedness of $\left\{u_{n}\right\}$ we immediately obtain

$$
\lim _{n \rightarrow \infty}\left\|u_{n}-W u_{n}\right\|=0
$$

Step 5. We show that

$$
\limsup _{n \rightarrow \infty}\left\langle(\gamma f-A) x^{*}, x_{n}-x^{*}\right\rangle \leq 0
$$

where $x^{*}$ uniquely solves the minimization problem (3.3). 
Indeed, as previously, we have proven that $x^{*}$ is the unique fixed point of the mapping $P_{\Omega}(\gamma f+(I-A))\left(\right.$ i.e., $\left.x^{*}=P_{\Omega}(\gamma f+(I-A)) x^{*}\right)$. That is, $x^{*}$ is the unique solution of VIP (3.2). Equivalently, $x^{*}$ is the unique solution of the minimization problem (3.3).

First, we observe that there exists a subsequence $\left\{x_{n_{i}}\right\}$ of $\left\{x_{n}\right\}$ such that

$$
\limsup _{n \rightarrow \infty}\left\langle(\gamma f-A) x^{*}, x_{n}-x^{*}\right\rangle=\lim _{i \rightarrow \infty}\left\langle(\gamma f-A) x^{*}, x_{n_{i}}-x^{*}\right\rangle .
$$

Since $\left\{x_{n_{i}}\right\}$ is bounded, there exists a subsequence $\left\{x_{n_{i_{j}}}\right\}$ of $\left\{x_{n_{i}}\right\}$ which converges weakly to some $w$. Without loss of generality, we may assume that $x_{n_{i}} \rightarrow w$. From (3.17), we have that $u_{n_{i}} \rightarrow w$. By (3.15) and (3.19) we have that $\left\|G u_{n}-u_{n}\right\| \rightarrow 0$ and $\left\|W u_{n}-u_{n}\right\| \rightarrow 0$ as $n \rightarrow \infty$. Utilizing similar arguments to those of (3.4), we know that $G$ is nonexpansive. Hence, by Lemma 2.5 we obtain $w \in \operatorname{Fix}(G)=\Gamma$ and $w \in \operatorname{Fix}(W)=\bigcap_{n=1}^{\infty} \operatorname{Fix}\left(T_{n}\right)$ (due to Lemma 2.4). Next, we prove that $w \in \operatorname{MEP}(F, \varphi)$. As a matter of fact, from $u_{n}=T_{r_{n}}^{(F, \varphi)}\left(I-r_{n} A\right) x_{n}$, we know that

$$
F\left(u_{n}, y\right)+\varphi(y)-\varphi\left(u_{n}\right)+\frac{1}{r_{n}}\left\langle u_{n}-x_{n}, y-u_{n}\right\rangle \geq 0, \quad \forall y \in C .
$$

From (A2) it follows that

$$
\varphi(y)-\varphi\left(u_{n}\right)+\frac{1}{r_{n}}\left\langle u_{n}-x_{n}, y-u_{n}\right\rangle \geq F\left(y, u_{n}\right), \quad \forall y \in C .
$$

Replacing $n$ by $n_{i}$, we have

$$
\varphi(y)-\varphi\left(u_{n_{i}}\right)+\left\langle\frac{u_{n_{i}}-x_{n_{i}}}{r_{n_{i}}}, y-u_{n_{i}}\right\rangle \geq F\left(y, u_{n_{i}}\right), \quad \forall y \in C .
$$

Put $u_{t}=t y+(1-t) w$ for all $t \in(0,1]$ and $y \in C$. Then, from (3.21) we have

$$
0 \geq-\varphi\left(u_{t}\right)+\varphi\left(u_{n_{i}}\right)-\left\langle\frac{u_{n_{i}}-x_{n_{i}}}{r_{n_{i}}}, u_{t}-u_{n_{i}}\right\rangle+F\left(u_{t}, u_{n_{i}}\right) .
$$

So, from (A4), the weak lower semicontinuity of $\varphi, \frac{u_{n_{i}}-x_{n_{i}}}{r_{n_{i}}} \rightarrow 0$ and $u_{n_{i}} \rightarrow w$, we have

$$
0 \geq-\varphi\left(u_{t}\right)+\varphi(w)+F\left(u_{t}, w\right) \quad \text { as } i \rightarrow \infty .
$$

From (A1), (A4) and (3.22) we also have

$$
\begin{aligned}
0 & =F\left(u_{t}, u_{t}\right)+\varphi\left(u_{t}\right)-\varphi\left(u_{t}\right) \\
& \leq t F\left(u_{t}, y\right)+(1-t) F\left(u_{t}, w\right)+t \varphi(y)+(1-t) \varphi(w)-\varphi\left(u_{t}\right) \\
& =t\left[F\left(u_{t}, y\right)+\varphi(y)-\varphi\left(u_{t}\right)\right]+(1-t)\left[F\left(u_{t}, w\right)+\varphi(w)-\varphi\left(u_{t}\right)\right] \\
& \leq t\left[F\left(u_{t}, y\right)+\varphi(y)-\varphi\left(u_{t}\right)\right]
\end{aligned}
$$

and hence

$$
0 \leq F\left(u_{t}, y\right)+\varphi(y)-\varphi\left(u_{t}\right)
$$


Letting $t \rightarrow 0$, we have, for each $y \in C$,

$$
0 \leq F(w, y)+\varphi(y)-\varphi(w)
$$

This implies that $w \in \operatorname{MEP}(F, \varphi)$. Therefore, $w \in \bigcap_{n=1}^{\infty} \operatorname{Fix}\left(T_{n}\right) \cap \operatorname{MEP}(F, \varphi) \cap \Gamma:=\Omega$. Consequently, from (3.2) and (3.20) we have

$$
\limsup _{n \rightarrow \infty}\left\langle(\gamma f-A) x^{*}, x_{n}-x^{*}\right\rangle=\lim _{i \rightarrow \infty}\left\langle(\gamma f-A) x^{*}, w-x^{*}\right\rangle \leq 0 .
$$

Step 6. Finally, we show that $x_{n} \rightarrow x^{*} \in \Omega$ as $n \rightarrow \infty$.

Indeed, taking into account that $x_{n+1}=P_{C} y_{n}$ and $y_{n}=\alpha_{n} \gamma f\left(x_{n}\right)+\beta_{n} x_{n}+\left(\left(1-\beta_{n}\right) I-\right.$ $\left.\alpha_{n} A\right) W_{n} G u_{n}$, we obtain from (3.4) and Proposition 2.1(i) that

$$
\begin{aligned}
\left\|x_{n+1}-x^{*}\right\|^{2} & \left\langle P_{C} y_{n}-y_{n}, P_{C} y_{n}-x^{*}\right\rangle+\left\langle y_{n}-x^{*}, x_{n+1}-x^{*}\right\rangle \\
\leq & \left\langle y_{n}-x^{*}, x_{n+1}-x^{*}\right\rangle \\
= & \left\langle\alpha_{n}\left(\gamma f\left(x_{n}\right)-A x^{*}\right)+\beta_{n}\left(x_{n}-x^{*}\right)+\left(\left(1-\beta_{n}\right) I-\alpha_{n} A\right)\left(W_{n} G u_{n}-x^{*}\right), x_{n+1}-x^{*}\right\rangle \\
= & \left.\alpha_{n} \gamma\left(f\left(x_{n}\right)-f\left(x^{*}\right)\right)+\beta_{n}\left(x_{n}-x^{*}\right)+\left(\left(1-\beta_{n}\right) I-\alpha_{n} A\right)\left(W_{n} G u_{n}-x^{*}\right), x_{n+1}-x^{*}\right\rangle \\
& +\alpha_{n}\left\langle(\gamma f-A) x^{*}, x_{n+1}-x^{*}\right\rangle \\
\leq & \left\|\alpha_{n} \gamma\left(f\left(x_{n}\right)-f\left(x^{*}\right)\right)+\beta_{n}\left(x_{n}-x^{*}\right)+\left(\left(1-\beta_{n}\right) I-\alpha_{n} A\right)\left(W_{n} G u_{n}-x^{*}\right)\right\|\left\|x_{n+1}-x^{*}\right\| \\
& +\alpha_{n}\left\langle(\gamma f-A) x^{*}, x_{n+1}-x^{*}\right\rangle \\
\leq & {\left[\alpha_{n} \gamma\left\|f\left(x_{n}\right)-f\left(x^{*}\right)\right\|+\beta_{n}\left\|x_{n}-x^{*}\right\|+\left\|\left(1-\beta_{n}\right) I-\alpha_{n} A\right\|\left\|W_{n} G u_{n}-x^{*}\right\|\right] } \\
& \times\left\|x_{n+1}-x^{*}\right\|+\alpha_{n}\left((\gamma f-A) x^{*}, x_{n+1}-x^{*}\right\rangle \\
\leq & {\left[\alpha_{n} \gamma l\left\|x_{n}-x^{*}\right\|+\beta_{n}\left\|x_{n}-x^{*}\right\|+\left(1-\beta_{n}-\alpha_{n} \bar{\gamma}\right)\left\|u_{n}-x^{*}\right\|\right]\left\|x_{n+1}-x^{*}\right\| } \\
& +\alpha_{n}\left\langle(\gamma f-A) x^{*}, x_{n+1}-x^{*}\right\rangle \\
\leq & {\left[\alpha_{n} \gamma l\left\|x_{n}-x^{*}\right\|+\beta_{n}\left\|x_{n}-x^{*}\right\|+\left(1-\beta_{n}-\alpha_{n} \bar{\gamma}\right)\left\|x_{n}-x^{*}\right\|\right]\left\|x_{n+1}-x^{*}\right\| } \\
& +\alpha_{n}\left\langle(\gamma f-A) x^{*}, x_{n+1}-x^{*}\right\rangle \\
= & \left(1-\alpha_{n}(\bar{\gamma}-\gamma l)\right)\left\|x_{n}-x^{*}\right\|\left\|x_{n+1}-x^{*}\right\|+\alpha_{n}\left|(\gamma f-A) x^{*}, x_{n+1}-x^{*}\right\rangle \\
\leq & \frac{1}{2}\left(1-\alpha_{n}(\bar{\gamma}-\gamma l)\right)\left(\left\|x_{n}-x^{*}\right\|^{2}+\left\|x_{n+1}-x^{*}\right\|^{2}\right)+\alpha_{n}\left\langle(\gamma f-A) x^{*}, x_{n+1}-x^{*}\right\rangle,
\end{aligned}
$$

which immediately implies that

$$
\begin{aligned}
\left\|x_{n+1}-x^{*}\right\|^{2} \leq & \frac{1-\alpha_{n}(\bar{\gamma}-\gamma l)}{1+\alpha_{n}(\bar{\gamma}-\gamma l)}\left\|x_{n}-x^{*}\right\|^{2}+\frac{\alpha_{n}}{1+\alpha_{n}(\bar{\gamma}-\gamma l)}\left\langle(\gamma f-A) x^{*}, x_{n+1}-x^{*}\right\rangle \\
= & \left(1-\frac{2 \alpha_{n}(\bar{\gamma}-\gamma l)}{1+\alpha_{n}(\bar{\gamma}-\gamma l)}\right)\left\|x_{n}-x^{*}\right\|^{2} \\
& +\frac{2 \alpha_{n}(\bar{\gamma}-\gamma l)}{1+\alpha_{n}(\bar{\gamma}-\gamma l)} \cdot \frac{1}{2(\bar{\gamma}-\gamma l)}\left\langle(\gamma f-A) x^{*}, x_{n+1}-x^{*}\right\rangle \\
= & \left(1-\gamma_{n}\right)\left\|x_{n}-x^{*}\right\|^{2}+\sigma_{n} \gamma_{n},
\end{aligned}
$$


where $\gamma_{n}=\frac{2 \alpha_{n}(\bar{\gamma}-\gamma l)}{1+\alpha_{n}(\bar{\gamma}-\gamma l)}$ and $\sigma_{n}=\frac{1}{2(\bar{\gamma}-\gamma l)}\left\langle(\gamma f-A) x^{*}, x_{n+1}-x^{*}\right\rangle$. Note that $\sum_{n=1}^{\infty} \alpha_{n}=\infty$ implies $\sum_{n=1}^{\infty} \gamma_{n} \geq \frac{2(\bar{\gamma}-\gamma l)}{1+(\bar{\gamma}-\gamma l)} \cdot \sum_{n=1}^{\infty} \alpha_{n}=\infty$ and that (3.23) leads to

$$
\limsup _{n \rightarrow \infty} \sigma_{n}=\limsup _{n \rightarrow \infty} \frac{1}{2(\bar{\gamma}-\gamma l)}\left\langle(\gamma f-A) x^{*}, x_{n+1}-x^{*}\right\rangle \leq 0 .
$$

Applying Lemma 2.8 to (3.24), we infer that the sequence $\left\{x_{n}\right\}$ converges strongly to $x^{*}$. This completes the proof.

Putting $T_{n} \equiv I$ the identity mapping, and $l=\alpha \in(0,1)$ in Theorem 3.1, we have the following result.

Corollary 3.1 Let $C$ be a nonempty closed convex subset of a real Hilbert space $H$. Let $F$ be a bifunction from $C \times C$ to $R$ satisfying conditions (A1)-(A4), and let $\varphi: C \rightarrow R$ be a lower semicontinuous and convex function with restriction (B1) or (B2). Let the mapping $B_{i}$ : $C \rightarrow H$ be $\zeta_{i}$-inverse strongly monotone for $i=1,2$. Let $A$ be a $\bar{\gamma}$-strongly positive bounded linear operator on $H$ and $f: H \rightarrow H$ be an $\alpha$-contraction with $0<\gamma<\frac{\bar{\gamma}}{\alpha}$. Assume that $\Omega:=$ $\operatorname{MEP}(F, \varphi) \cap \Gamma \neq \emptyset$, where $\Gamma$ is the fixed point set of the mapping $G=P_{C}\left(I-\mu_{1} B_{1}\right) P_{C}(I-$ $\left.\mu_{2} B_{2}\right)$ with $\mu_{i} \in\left(0,2 \zeta_{i}\right)$ for $i=1,2$. Let $\left\{\alpha_{n}\right\}$ and $\left\{\beta_{n}\right\}$ be two sequences in $(0,1)$ and $\left\{r_{n}\right\}$ be a sequence in $(0, \infty)$ such that:

(i) $\lim _{n \rightarrow \infty} \alpha_{n}=0, \sum_{n=1}^{\infty} \alpha_{n}=\infty$ and $\sum_{n=1}^{\infty}\left|\alpha_{n+1}-\alpha_{n}\right|<\infty$;

(ii) $0<\liminf _{n \rightarrow \infty} \beta_{n} \leq \limsup _{n \rightarrow \infty} \beta_{n}<1$ and $\sum_{n=1}^{\infty}\left|\beta_{n+1}-\beta_{n}\right|<\infty$;

(iii) $\liminf _{n \rightarrow \infty} r_{n}>0$ and $\sum_{n=1}^{\infty}\left|r_{n+1}-r_{n}\right|<\infty$.

Given $x_{1} \in H$ arbitrarily, the sequences $\left\{x_{n}\right\}$ and $\left\{u_{n}\right\}$ generated iteratively by

$$
\left\{\begin{array}{l}
F\left(u_{n}, y\right)+\varphi(y)-\varphi\left(u_{n}\right)+\frac{1}{r_{n}}\left\langle y-u_{n}, u_{n}-x_{n}\right\rangle \geq 0, \quad \forall y \in C, \\
x_{n+1}=P_{C}\left[\alpha_{n} \gamma f\left(x_{n}\right)+\beta_{n} x_{n}+\left(\left(1-\beta_{n}\right) I-\alpha_{n} A\right) G u_{n}\right], \quad \forall n \geq 1,
\end{array}\right.
$$

converge strongly to $x^{*} \in \Omega$, which is the unique solution of the VIP

$$
\left\langle(A-\gamma f) x^{*}, x^{*}-x\right\rangle \leq 0, \quad \forall x \in \Omega
$$

or, equivalently, the unique solution of the minimization problem

$$
\min _{x \in \Omega} \frac{1}{2}\langle A x, x\rangle-h(x)
$$

where $h$ is a potential function for $\gamma f$.

Putting $\varphi \equiv 0$ and $l=\alpha \in(0,1)$ in Theorem 3.1 , we have the following result.

Corollary 3.2 Let $C$ be a nonempty closed convex subset of a real Hilbert space $H$. Let $F$ be a bifunction from $C \times C$ to $R$ satisfying conditions (A1)-(A4). Let the mapping $B_{i}: C \rightarrow H$ be $\zeta_{i}$-inverse strongly monotone for $i=1,2$. Let $\left\{T_{n}\right\}_{n=1}^{\infty}$ be a sequence of nonexpansive selfmappings on $C$ and $\left\{\lambda_{n}\right\}$ be a sequence in $(0, b]$ for some $b \in(0,1)$. Let $A$ be a $\bar{\gamma}$-strongly positive bounded linear operator on $H$ and $f: H \rightarrow H$ be an $\alpha$-contraction with $0<\gamma<\frac{\bar{\gamma}}{\alpha}$. Let $W_{n}$ be the $W$-mapping defined by (1.13). Assume that $\Omega:=\bigcap_{n=1}^{\infty} F\left(T_{n}\right) \cap \operatorname{EP}(F) \cap \Gamma \neq \emptyset$, where $\Gamma$ is the fixed point set of the mapping $G=P_{C}\left(I-\mu_{1} B_{1}\right) P_{C}\left(I-\mu_{2} B_{2}\right)$ with $\mu_{i} \in\left(0,2 \zeta_{i}\right)$ 
for $i=1,2$. Let $\left\{\alpha_{n}\right\}$ and $\left\{\beta_{n}\right\}$ be two sequences in $(0,1)$ and $\left\{r_{n}\right\}$ be a sequence in $(0, \infty)$ such that:

(i) $\lim _{n \rightarrow \infty} \alpha_{n}=0, \sum_{n=1}^{\infty} \alpha_{n}=\infty$ and $\sum_{n=1}^{\infty}\left|\alpha_{n+1}-\alpha_{n}\right|<\infty$;

(ii) $0<\liminf _{n \rightarrow \infty} \beta_{n} \leq \limsup _{n \rightarrow \infty} \beta_{n}<1$ and $\sum_{n=1}^{\infty}\left|\beta_{n+1}-\beta_{n}\right|<\infty$;

(iii) $\liminf _{n \rightarrow \infty} r_{n}>0$ and $\sum_{n=1}^{\infty}\left|r_{n+1}-r_{n}\right|<\infty$.

Given $x_{1} \in H$ arbitrarily, the sequences $\left\{x_{n}\right\}$ and $\left\{u_{n}\right\}$ generated iteratively by

$$
\left\{\begin{array}{l}
F\left(u_{n}, y\right)+\frac{1}{r_{n}}\left\langle y-u_{n}, u_{n}-x_{n}\right\rangle \geq 0, \quad \forall y \in C, \\
x_{n+1}=P_{C}\left[\alpha_{n} \gamma f\left(x_{n}\right)+\beta_{n} x_{n}+\left(\left(1-\beta_{n}\right) I-\alpha_{n} A\right) W_{n} G u_{n}\right], \quad \forall n \geq 1,
\end{array}\right.
$$

converge strongly to $x^{*} \in \Omega$, which is the unique solution of the VIP

$$
\left\langle(A-\gamma f) x^{*}, x^{*}-x\right\rangle \leq 0, \quad \forall x \in \Omega,
$$

or, equivalently, the unique solution of the minimization problem

$$
\min _{x \in \Omega} \frac{1}{2}\langle A x, x\rangle-h(x)
$$

where $h$ is a potential function for $\gamma f$.

Putting $B_{1} \equiv B_{2} \equiv 0$ in Corollary 3.1, we have the following result.

Corollary 3.3 Let $C$ be a nonempty closed convex subset of a real Hilbert space H. Let $F$ be a bifunction from $C \times C$ to $R$ satisfying conditions (A1)-(A4). Let $\left\{T_{n}\right\}_{n=1}^{\infty}$ be a sequence of nonexpansive self-mappings on $C$ and $\left\{\lambda_{n}\right\}$ be a sequence in $(0, b]$ for some $b \in(0,1)$. Let $A$ be a $\bar{\gamma}$-strongly positive bounded linear operator on $H$ and $f: H \rightarrow H$ be an $\alpha$-contraction with $0<\gamma<\frac{\bar{\gamma}}{\alpha}$. Let $W_{n}$ be the $W$-mapping defined by (1.13). Assume that $\Omega:=\bigcap_{n=1}^{\infty} F\left(T_{n}\right) \cap$ $\mathrm{EP}(F) \neq \emptyset$. Let $\left\{\alpha_{n}\right\}$ and $\left\{\beta_{n}\right\}$ be two sequences in $(0,1)$ and $\left\{r_{n}\right\}$ be a sequence in $(0, \infty)$ such that:

(i) $\lim _{n \rightarrow \infty} \alpha_{n}=0, \sum_{n=1}^{\infty} \alpha_{n}=\infty$ and $\sum_{n=1}^{\infty}\left|\alpha_{n+1}-\alpha_{n}\right|<\infty$;

(ii) $0<\liminf _{n \rightarrow \infty} \beta_{n} \leq \limsup _{n \rightarrow \infty} \beta_{n}<1$ and $\sum_{n=1}^{\infty}\left|\beta_{n+1}-\beta_{n}\right|<\infty$;

(iii) $\liminf _{n \rightarrow \infty} r_{n}>0$ and $\sum_{n=1}^{\infty}\left|r_{n+1}-r_{n}\right|<\infty$.

Given $x_{1} \in H$ arbitrarily, the sequences $\left\{x_{n}\right\}$ and $\left\{u_{n}\right\}$ generated iteratively by

$$
\left\{\begin{array}{l}
F\left(u_{n}, y\right)+\frac{1}{r_{n}}\left\langle y-u_{n}, u_{n}-x_{n}\right\rangle \geq 0, \quad \forall y \in C, \\
x_{n+1}=P_{C}\left[\alpha_{n} \gamma f\left(x_{n}\right)+\beta_{n} x_{n}+\left(\left(1-\beta_{n}\right) I-\alpha_{n} A\right) W_{n} u_{n}\right], \quad \forall n \geq 1
\end{array}\right.
$$

converge strongly to $x^{*} \in \Omega$, which is the unique solution of the VIP

$$
\left\langle(A-\gamma f) x^{*}, x^{*}-x\right\rangle \leq 0, \quad \forall x \in \Omega,
$$

or, equivalently, the unique solution of the minimization problem

$$
\min _{x \in \Omega} \frac{1}{2}\langle A x, x\rangle-h(x),
$$

where $h$ is a potential function for $\gamma f$. 


\section{Competing interests}

The authors declare that they have no competing interests.

\section{Authors' contributions}

All authors contributed equally and significantly in writing this article. All authors read and approved the final manuscript.

\section{Acknowledgements}

All the authors were partially supported by the National Science Foundation of China (11071169) and PhD Program

Foundation of the Ministry of Education of China (20123127110002).

\section{Received: 15 October 2013 Accepted: 11 March 2014 Published: 26 Mar 2014}

\section{References}

1. Moudaf, A: Viscosity approximation methods for fixed-points problems. J. Math. Anal. Appl. 241, 46-55 (2000)

2. Ceng, LC, Yao, JC: A hybrid iterative scheme for mixed equilibrium problems and fixed point problems. J. Comput. Appl. Math. 214, 186-201 (2008)

3. Chang, SS, Lee, HWJ, Chan, CK: A new method for solving equilibrium problem fixed point problem and variational inequality problem with application to optimization. Nonlinear Anal. 70, 3307-3319 (2009)

4. Zeng, LC, Yao, JC: Modified combined relaxation method for general monotone equilibrium problems in Hilbert spaces. J. Optim. Theory Appl. 131, 469-483 (2006)

5. Takahashi, S, Takahashi, W: Viscosity approximation methods for equilibrium problems and fixed point problems in Hilbert spaces. J. Math. Anal. Appl. 331, 506-515 (2007)

6. Yao, Y, Liou, YC, Yao, JC: Convergence theorem for equilibrium problems and fixed point problems of infinite family of nonexpansive mappings. Fixed Point Theory Appl. 2007, 064363 (2007)

7. Rattanaseeha, $K:$ The general iterative methods for equilibrium problems and fixed point problems of countable family of nonexpansive mappings in Hilbert spaces. J. Inequal. Appl. 2013, 153 (2013)

8. Ceng, LC, Yao, JC: A relaxed extragradient-like method for a generalized mixed equilibrium problem, a general system of generalized equilibria and a fixed point problem. Nonlinear Anal. 72, 1922-1937 (2010)

9. Ceng, LC, Guu, SM, Yao, JC: Hybrid iterative method for finding common solutions of generalized mixed equilibrium and fixed point problems. Fixed Point Theory Appl. 2012, 92 (2012)

10. Lions, JL, Stampacchia, G: Variational inequalities. Commun. Pure Appl. Math. 20, 493-512 (1967)

11. Zeng, LC: Iterative algorithms for finding approximate solutions for general strongly nonlinear variational inequalities J. Math. Anal. Appl. 187, 352-360 (1994)

12. Ceng, LC, Teboulle, M, Yao, JC: Weak convergence of an iterative method for pseudomonotone variational inequalities and fixed point problems. J. Optim. Theory Appl. 146, 19-31 (2010)

13. Zeng, LC: Iterative algorithm for finding approximate solutions to completely generalized strongly nonlinear quasivariational inequalities. J. Math. Anal. Appl. 201, 180-194 (1996)

14. Yao, Y, Yao, JC: On modified iterative method for nonexpansive mappings and monotone mappings. Appl. Math. Comput. 186, 1551-1558 (2007)

15. Plubtieng, S, Punpaeng, R: A general iterative method for equilibrium problems and fixed point problems in Hilbert spaces. J. Math. Anal. Appl. 336, 455-469 (2007)

16. Zeng, LC, Yao, JC: Strong convergence theorem by an extragradient method for fixed point problems and variational inequality problems. Taiwan. J. Math. 10, 1293-1303 (2006)

17. Ceng, LC, Wang, CY, Yao, JC: Strong convergence theorems by a relaxed extragradient method for a general system of variational inequalities. Math. Methods Oper. Res. 67, 375-390 (2008)

18. Xu, HK: Viscosity approximation methods for nonexpansive mappings. J. Math. Anal. Appl. 298, 279-291 (2004)

19. Marino, G, Xu, HK: A general iterative method for nonexpansive mapping in Hilbert spaces. J. Math. Anal. Appl. 318, 43-52 (2006)

20. Chen, R: Iterative schemes for fixed point computation of nonexpansive mappings. Abstr. Appl. Anal. 2012, 469270 (2012)

21. O'Hara, JG, Pillay, P, Xu, HK: Iterative approaches to convex feasibility problems in Banach spaces. Nonlinear Anal. 64 2022-2042 (2006)

22. Geobel, K, Kirk, WA: Topics on Metric Fixed-Point Theory. Cambridge University Press, Cambridge (1990)

23. Xu, HK: Iterative algorithms for nonlinear operators. J. Lond. Math. Soc. 66, 240-256 (2002)

10.1186/1687-1812-2014-80

Cite this article as: Wang et al.: General iterative algorithms for mixed equilibrium problems, variational inequalities and fixed point problems. Fixed Point Theory and Applications 2014, 2014:80 